\title{
Damage evolution in AA2124/SiC metal matrix composites under tension with consecutive unloadings
}

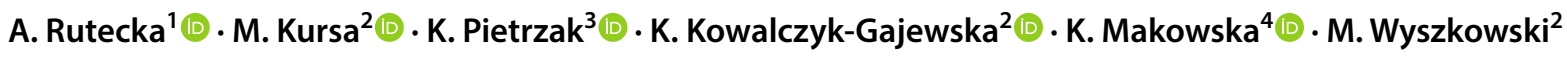

Received: 10 June 2020 / Revised: 11 September 2020 / Accepted: 26 September 2020

(c) The Author(s) 2020

\begin{abstract}
Nonlinear properties of metal matrix composites (MMCs) are studied. The research combines results of loading-unloading tensile tests, microstructural observations and numerical predictions by means of micromechanical mean-field models. AA2124/SiC metal matrix composites with $\mathrm{SiC}$ particles, produced by the Aerospace Metal Composites Ltd. (AMC) are investigated. The aluminum matrix is reinforced with $17 \%$ and $25 \%$ of $\mathrm{SiC}$ particles. The best conditions to evaluate the current elastic stiffness modulus have been assessed. Tensile tests were carried out with consecutive unloading loops to obtain actual tensile modulus and study degradation of elastic properties of the composites. The microstructure examination by scanning electron microscopy (SEM) showed a variety of phenomena occurring during composite deformation and possible sources of elastic stiffness reduction and damage evolution have been indicated. Two micromechanical approaches, the incremental Mori-Tanaka (MT) and self-consistent (SC) schemes, are applied to estimate effective properties of the composites. The standard formulations are extended to take into account elasto-plasticity and damage development in the metal phase. The method of direct linearization performed for the tangent or secant stiffness moduli is formulated. Predictions of both approaches are compared with experimental results of tensile tests in the elastic-plastic regime. The question is addressed how to perform the micromechanical modelling if the actual stress-strain curve of metal matrix is unknown.
\end{abstract}

Keywords Metal matrix composites $\cdot$ Tension with unloadings $\cdot$ Damage $\cdot$ Microstructure $\cdot$ Non-linear effective properties

\section{Introduction}

Materials such as metal matrix composites (MMCs) during exploitation sustain nucleation and accumulation of defects called damage. Damage can lead to unexpected failure of a component made of the material and cause accident that may severely influence human health and life. There are methods that allow to observe and quantify damage accumulation during experimental tests on specimens manufactured

A. Rutecka

a.rutecka@il.pw.edu.pl

1 Faculty of Civil Engineering, Warsaw University of Technology, Al. Armii Ludowej 16, 00-637 Warsaw, Poland

2 Institute of Fundamental Technological Research (IPPT PAN), Pawińskiego 5B, 02-106 Warsaw, Poland

3 Łukasiewicz Research Network - Institute of Precision Mechanics, Duchnicka 3, 01-796 Warsaw, Poland

4 Motor Transport Institute, Jagiellońska 80, 03-301 Warsaw, Poland from materials. One of such basic tests in which material damage can be characterized and which is standard and necessary to perform for materials is tensile test.

$\mathrm{SiC}$ particles are characterized by high stiffness, much higher than aluminum alloy. When we combine aluminum alloy with $\mathrm{SiC}$ ceramic particles, the $\mathrm{SiC}$ particles "carry" the load and they strengthen the composite and make it much stronger in comparison to the aluminum alloy [1]. However, a further increase of the ceramic-phase concentration in the composite may lead to a reduction in its mechanical properties, see e.g. [2].

Researchers observed that damage accumulation during tension depends on microstructure of the MMC and can be initiated and propagated by three damage mechanisms: fracture of reinforcement particles, matrix voiding as well as the particle/matrix debonding at the interface between two composite phases, what was discussed e.g. in [3]. Debonding may also result from voids occurring in the matrix at or close to the interface. The possibility of occurrence of reinforcement particles fracture as a predominant damage mechanism increases with an increase 
of reinforcement particles size or volume fraction [3]. Simultaneously, with a decrease of reinforcement particles size and volume fraction, microstructural damage changes from reinforcement fracture to matrix voiding localized near or at matrix-reinforcement interface [4]. Frequently, particle fracture takes place at contact points between two particles during tension and subsequently such arisen cracks open during loading. Matrix voids in MMC often develop in places between closely located reinforcement particles. In [5], 7049 aluminum alloy matrix reinforced with $15 \%$ of $\mathrm{SiC}$ patricles was studied. Scanning electron microscope in situ tensile tests were performed. Two main damage mechanisms such as fracture of $\mathrm{SiC}$ particles and particle-matrix interface decohesion were observed. It was noticed that in elongated and large particles, cracks formed easier and at beginning of plastic deformation while decohesion occurred less frequently and at larger values of plastic strains. Fracture was observed in places were more $\mathrm{SiC}$ particles were observed and distance between them was lower. Authors of [6] studied tensile properties of AA7075 aluminum alloy MMC with SiC particles as reinforcement. They reported that during composites, loading stress is transferred to reinforcement particles. When the stress is large enough, damage occurs as a failure at or near matrix-reinforcement interface or as a particles fracture. With applied load more particles fail and damage accumulates. Damaged particles do not support the load and act as voids increasing stress level in the unreinforced material. This can lead to voids nucleation and growth and subsequently to further failure. In [7], tensile tests of AA2124 aluminum alloy reinforced with $\mathrm{SiC}$ particles were discussed. The $\mathrm{SiC}$ particle cracking, decohesion at the particle-matrix interface and lattice damage coupled with residual stress effect, were recognized as main damage reasons. Fine microcracks initiated at low stresses at or near particle-matrix interfaces caused by non-uniform distribution of $\mathrm{SiC}$ particles were also reported. The latter shows another reason that can lead to MMC damage i.e. formation of reinforcement particle clusters during MMC production observed e.g. for $\mathrm{Al} / \mathrm{SiC}$ composites and reported in [8] and [9]. Such particles in clusters can be not sufficiently bonded to the matrix and weaken the material.

Additionally, the microstructure feature, which may next lead to damage development, is the porosity that appear during production process e.g. due to mismatch in the thermal expansion coefficients of metallic matrix and ceramic particles [10]. This effect influences especially an interface between ceramic particles and metallic matrix. Another important phenomenon is the precipitations growth within grains and at grain boundaries of metallic phase caused by heat treatment. An intermetallic compound phase can form during heat treatment, increasing hardness and reducing ductility of the composites [10].

One of direct methods to assess damage evolution and its mechanisms is the observation of the fracture surface resulting from a mechanical test, performed on the microscopic level using a scanning electron microscope (SEM). Moreover, the examination of microstructure on the crosssections near the tensile fracture surface, as well as at a long distance from it, is also needed. In composites reinforced with hard particles in the whole volume, the following three mechanisms of crack formation dominate: deflection on the reinforcing particles, bridging of cracks by these particles and branching of cracks on reinforcing particles [11-15]. Composites with a $\mathrm{Zn}-\mathrm{Mg}-\mathrm{Cu}$ alloy matrix, reinforced with $\mathrm{SiC}$ particles as well as $\mathrm{Zn}-\mathrm{Mg}-\mathrm{Cu}$ alloy without the reinforcing phase, both obtained by powder metallurgy, were studied in [11]. Based on a study of crack bridging in composite material, the simple models were developed to predict the magnitude of crack-tip shielding during fatigue-crack growth [11]. Microstructure and mechanical properties of $\mathrm{TiSi}_{2}-\mathrm{SiC}_{-} \mathrm{Ti}_{3} \mathrm{SiC}_{2}$ composites prepared by spark plasma sintering were analyzed in [12]. The improvement in fracture toughness was attributed to crack deflection and crack bridging resulted from nano-SiC particles and layered $\mathrm{Ti}_{3} \mathrm{SiC}_{2}$ grains. The research presented in [13] concerned Mo ( $\mathrm{Si}$, $\mathrm{Al})_{2}-\mathrm{SiC}$ composites prepared by in situ reaction of $\mathrm{MoSi}_{2}$, $\mathrm{Al}$ and $\mathrm{C}$. It was found that the $\mathrm{SiC}$ phase may take the shape of whiskers and particles act as deflection and bridging elements improving the toughness of the examined composites. The authors of [14] studied the fatigue crack propagation (FCP) of aluminum matrix composites and casting aluminum alloys. Among others it was shown that in $\mathrm{SiCp} /$ $\mathrm{Al}$ composites, cracks propagated avoiding $\mathrm{SiC}$ particles and predominantly within the matrix, while in the casting aluminum alloy, debonding of eutectic Si particles was the main feature and cracks grew to link debonded particles along dendrite cells that caused remarkable crack deflections [14]. The authors of [15] examined the fracture toughness of metal-reinforced alumina. By the use of ductile particles in a hard ceramic matrix, significant improvements in fracture toughness due to plastic deformation of the metallic phase has been obtained. However, there are metals that enhance the toughness of a ceramic better than others; these are those metals that have similar densities to alumina, because they help to obtain fine and homogeneous microstructures after sintering. From the fracture toughness measurements and microstructural observations, finally it can be commented that the toughening mechanism in $\mathrm{Al}_{2} \mathrm{O}_{3}$ /metal reinforced composites is due to crack bridging and crack deflection [15].

Especially the bridging mechanism observed in metal matrix composites plays an important role during 
degradation of their microstructure. It can inhibit the further potential development of cracks in the remaining microstructure of the material. In the paper, the aim of microstructure examination was to assess the microstructure defects and their mechanisms observed after tensile tests performed with consecutive unloadings.

Continuum damage mechanics (CDM) can be used to describe phenomenologically and macroscopically the effect of microscopic damage. The framework uses damage parameter $d$ as an internal state variable [16]. It is important to choose an adequate physical parameter that would characterize damage evolution during material exploitation. One of such physical parameters is elastic modulus. Its change can be evaluated from several unloading-reloading cycles under tensile test, what was presented e.g. in [3]. Elastic modulus is used to estimate damage parameter since its value decreases with an increase of applied tensile stress above the damage initiation stress i.e. an increase in damage accumulation. Damage parameter $d$ based on elastic modulus can be calculated as [16]

$d=1-E / E_{0}$,

where $E$ denotes the actual elastic modulus of damaged material, in the rest of the work it is called elastic modulus. Quantity $E_{0}$ is Young's modulus-an initial elastic modulus of the undamaged material.

Following the CDM paradigm identification of damage evolution in the material can be based on measuring the degradation of the elastic modulus during deformation $[17,18]$. Procedure of damage evolution measurements is still a challenging task $[19,20]$. The present paper contains an original methodology of damage identification in the MMCs. The method is based on a standard measurement of the elastic modulus degradation in an uniaxial tension carried out in quasi-static conditions. However, the uniaxial tension tests are performed with double consecutive unloading loops contrary to single unloading performed classically. The unloading loops are carried out in certain selected intervals of total strain up to zero stress level. The series of unloading loops are called "primary" and "secondary". Material response during the primary unloading loops can be characterised as nonlinear what indicates occurrence of dissipation in the material. That is why, it is difficult to obtain linear properties from the entire primary unloading loops. Specimen response in the course of secondary unloading loops is linear in most parts of their lengths. However, the question remains why the secondary loops are more linear than primary ones. It can be stated that in the observed ranges, material behaviour in the secondary loops is dissipation-free or dissipation effects are negligible-strain hardening increases the value of the yield stress and material remains in the elastic regime contrary to the primary loops, in which most probably due to kinematic hardening, plastic yielding is initiated during the loading reversal. Observed linearity of secondary unloadings can also indicate mutual cancellation of damage and plasticity/dissipation effects. Simultaneously, during second unloadings (similarly to fatigue tests observations), cyclic hardening was identified what influences the shapes of secondary loops making them more linear. The question arose: which loops the primary or the secondary ones are better suited for the assessment of elastic modulus and damage parameter. Analysis of results has led to the proposal of the method of damage identification in MMCs. The proposed solution has been supported by the predictions of micromechanical modelling.

Selection of the proper analytical or computational modelling procedure for the specific composite is still a challenge. A number of analytical methods for estimation of non-linear effective mechanical properties are available on the market, cf. [21]. A wide review of the computational schemes for predicting the non-linear effective properties of a heterogeneous material and current challenges was conducted in [22]. One of the leading simulation approaches is FE-based homogenization whose principles were first formulated in [23]. Such approach may be also applied to the periodic heterogeneous microstructures like in sandwich panels involving honeycomb cores discussed in [24]. As concern analysis of damage evolution different simulation tools have been applied for metal-matrix composites [25] and ceramic-matrix composites [26]. There exist also numerous analytical or numerical micromechanical analyses in which brittle fracture of particles, e.g. [27] and [28] or particle debonding on the matrix-inclusion interface, e.g. [29] and [30], are considered as basic damage mechanisms in metal-matrix composites. It can be mentioned that, when ductile failure of the matrix in terms of micro-voiding is considered yet another way of modelling is applied in the literature, in which the metal matrix follows the Gurson model [31].

In the present work, experimental and modelling investigations have been applied for identification of non-linear properties, with regard to damage evolution in composites. Due to computational efficiency, the analytical mean-field estimates of effective properties are applied [32]. Based on experimental findings, damage is considered as degradation of bulk and shear moduli of metallic matrix. To this end, the method and algorithm developed in [32] is extended. The model of damage evolution fits into the CDM framework and can be categorized as a direct simplified model according to the terminology proposed in [33]. In [32], the concept of $0 \%$ composite was introduced defined as a pure matrix material obtained under the same processing conditions as a given two phase composite. Because samples of such material are not available in the current research, the novel procedure of matrix phase identification based on the composite results has been worked out. 
The paper is organized as follows: the second section contains description of the composites; in the third section, experimental procedure and results of tensile tests are presented; the fourth one comprises microstructure observations; the fifth numerical modelling and the last one (the sixth) summary and conclusions.

\section{Materials}

The AA2124 aluminium alloy-based metal matrix composites (MMCs) with 17\% (AMC217xe) and 25\% (AMC225xe) of $\mathrm{SiC}$ particles content were tested [34, 35]. As informed by the producer, the average reinforcement particles size was equal to about $3 \mu \mathrm{m}$. The materials were produced by AMC Aerospace Metal Composites Ltd., Farnborough (United Kingdom). During the MMCs production, metal powders and $\mathrm{SiC}$ particles were subjected to high energy mixing, hot isostatic compaction, forging and T6 CWQ (cold water quenching) heat treatment. The chemical composition of the aluminium matrix is presented in [36].

\section{Experimental procedure and results of tensile tests}

Strain-controlled tensile tests with consecutive unloadings for the AA2124/SiC MMCs were carried out on a servohydraulic testing machine MTS 858 (Fig. 1) with strain rate equal to $0.0002 \mathrm{~s}^{-1}$ [35]. Flat specimens with rectangular gage cross section were manufactured and tested. Experimental investigations were carried out on three specimens for each composite. The first specimen was subjected to tension without unloadings, the two others to tension with multiple unloadings.

The specimens were named below using the following nomenclature:

- numbers 17 and 25 stand for percentage content of $\mathrm{SiC}$ reinforcement;

- xe stands for coarser $(3 \mu \mathrm{m}) \mathrm{SiC}$ particles;

- $\mathrm{zm}$ and $\mathrm{p}$ stand for a shape of specimen that was manufactured;

- the final number is a specimen number.

Tensile stress-strain curves for the composites are presented in Figs. 2a and 3a. Better (higher) tensile properties such as the Young's modulus, yield stress and ultimate tensile strength were obtained for the MMC with higher SiC content. Only strain to failure was higher for the composite with lower SiC content. Such behavior of tensile properties follows observations for similar MMCs made by other researchers, e.g. [1]. The imposed strain as a function of time during one of AA $2124+25 \% \mathrm{SiC}$ tensile test is presented in Fig. 2b.

Several unloadings were performed during tension-i.e., eight "primary unloadings" for engineering strain levels equal to: $0.05 ; 0.1 ; 0.15 ; 0.5 ; 1 ; 2 ; 3$ and $4 \%$ and four "secondary unloadings" for engineering strain levels equal to: 1 , 2, 3, and 4\% (Figs. 2a, 3, 4, 5, 6).

Primary and secondary unloadings were performed for strain levels equal to $1,2,3$, and $4 \%$. Let us describe the procedure of two consecutive unloadings for the strain level of $1 \%$. When the engineering strain reaches specified value, i.e. $1 \%$, the unloading is started (the strain is decreasing in Fig. 2b). It is called "primary unloading". It is finished
Fig. 1 Tensile test facilities: (a) servo-hydraulic testing machine MTS 858; (b) specimen with an extensometer mounted on it (a)

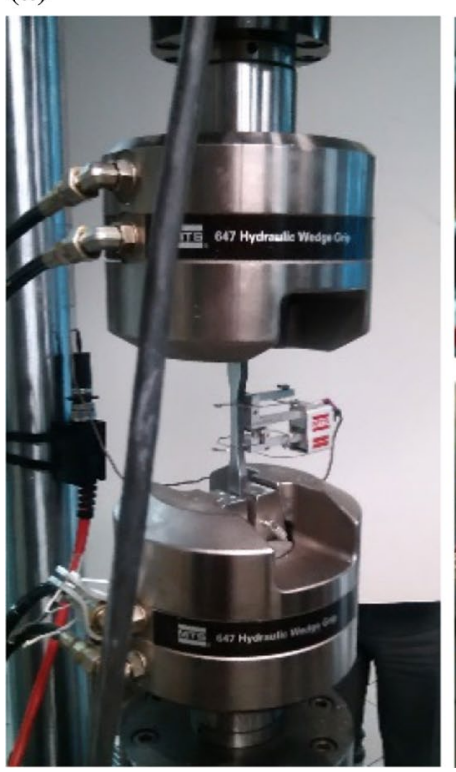

(b)

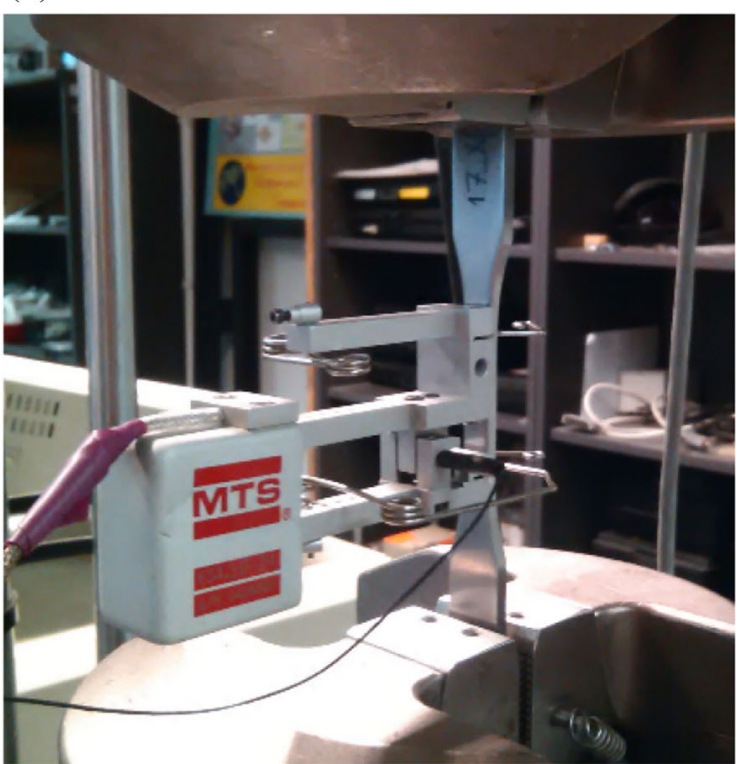


(a)

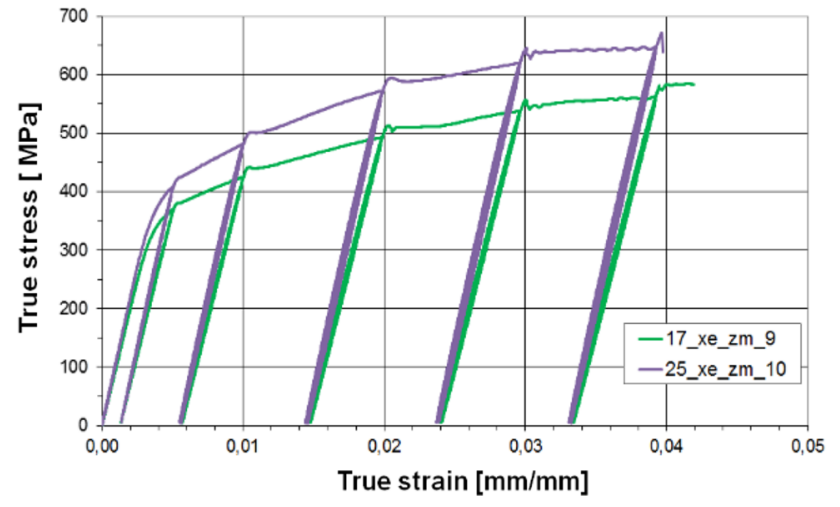

(b)

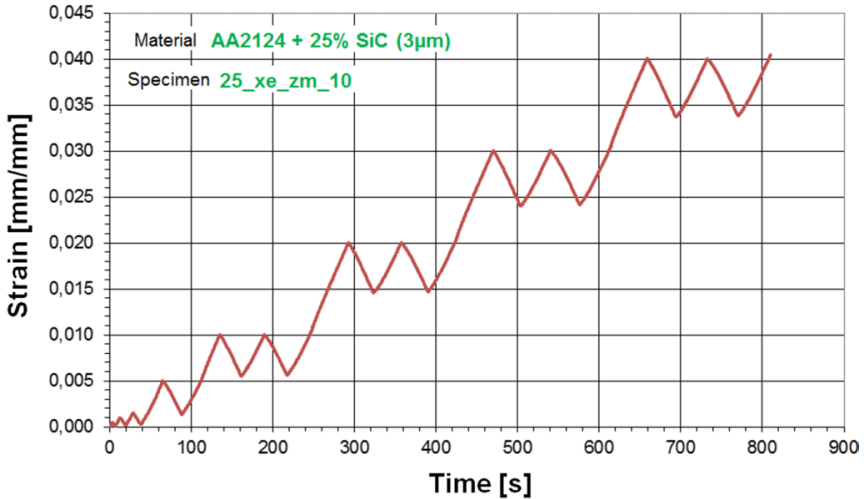

Fig. 2 a Comparison of tensile true stress-true strain curves for AA2124+17\% SiC and AA2124+25\%SiC. b Imposed strain as a function of time during AA2 $124+25 \% \mathrm{SiC}$ tensile test

(a)

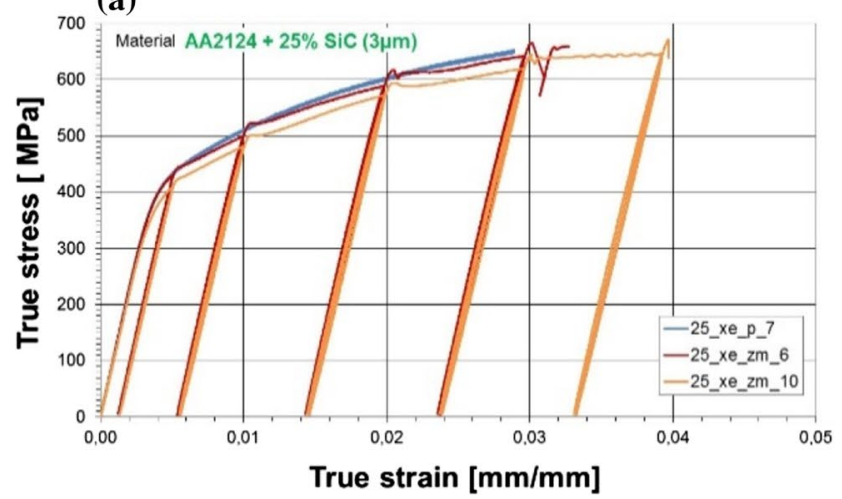

(b)

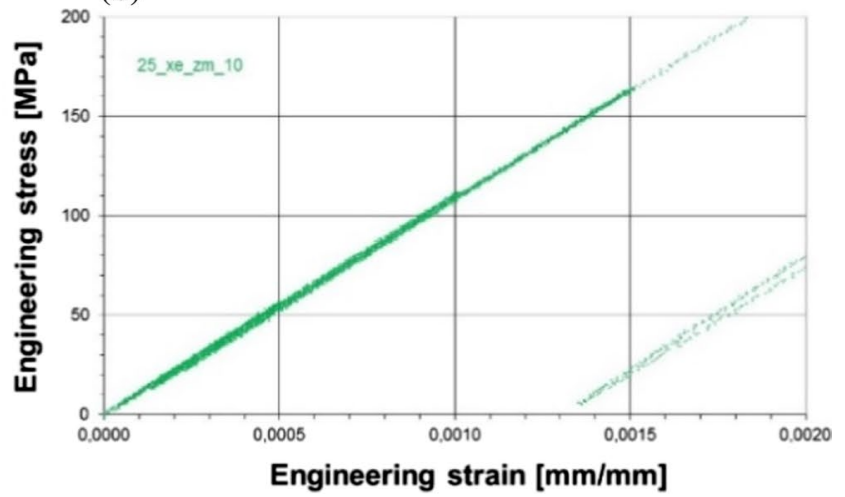

Fig. 3 AA2124+25\%SiC: (a) tensile stress-strain curves with and without unloadings; (b) three first unloadings in elastic range for specimen 25_xe_zm_10

(a)

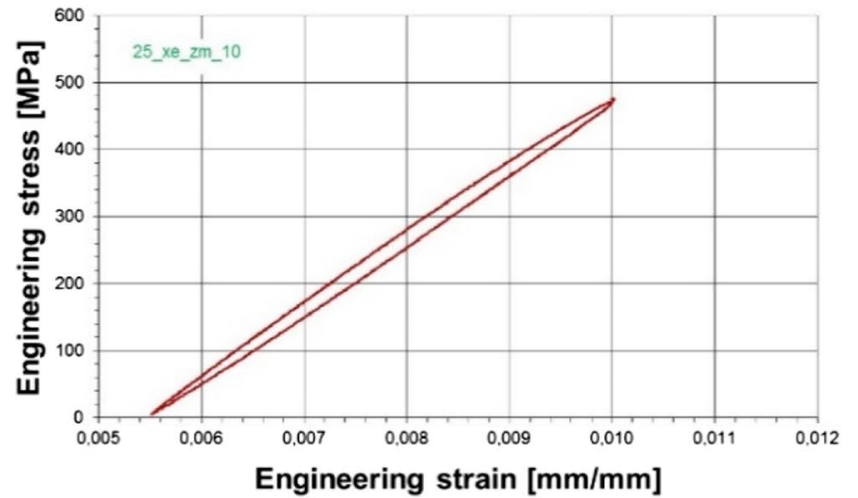

(b)

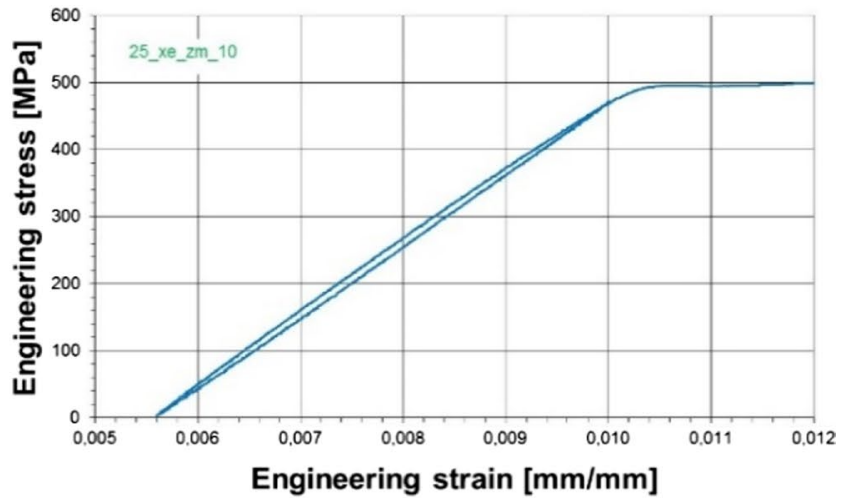

Fig. 4 AA2124+25\%SiC, specimen 25_xe_zm_10: (a) hysteresis loop—primary unloading after $1 \%$ of engineering strain; (b) hysteresis loop— secondary unloading after $1 \%$ of engineering strain 
(a)

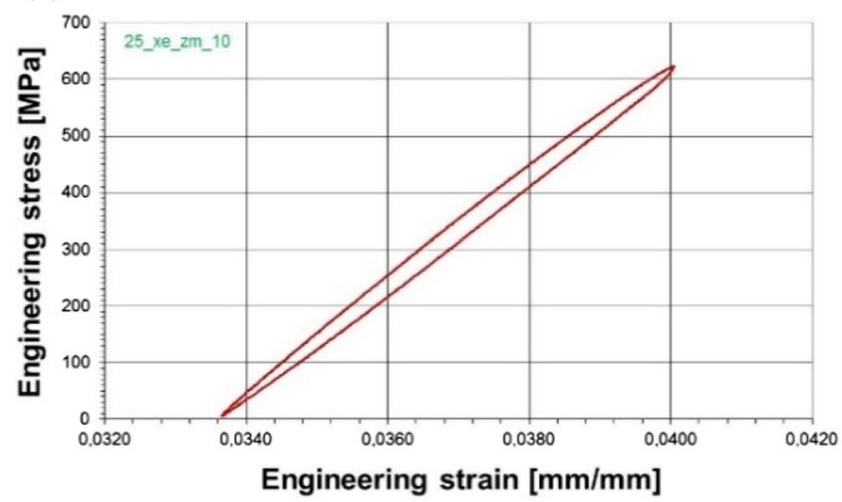

(b)

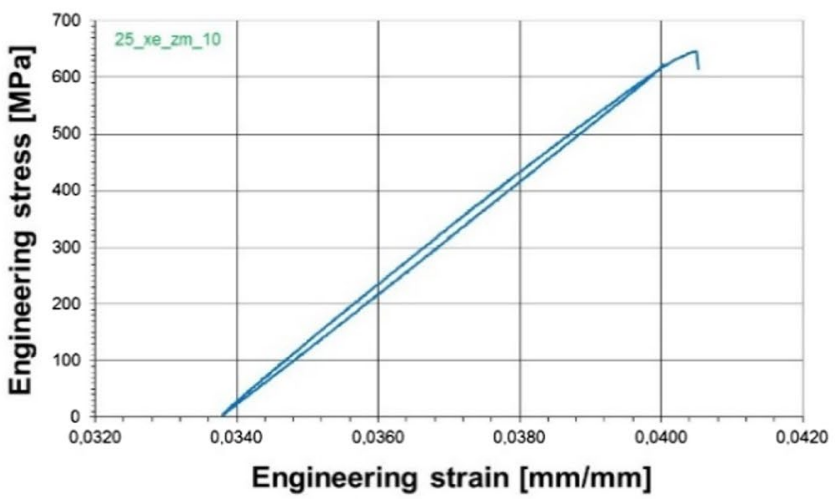

Fig. 5 AA2124 + 25\%SiC, specimen 25_xe_zm_10: (a) hysteresis loop—primary unloading after 4\% of engineering strain; (b) hysteresis loop— secondary unloading after $4 \%$ of engineering strain

(a)

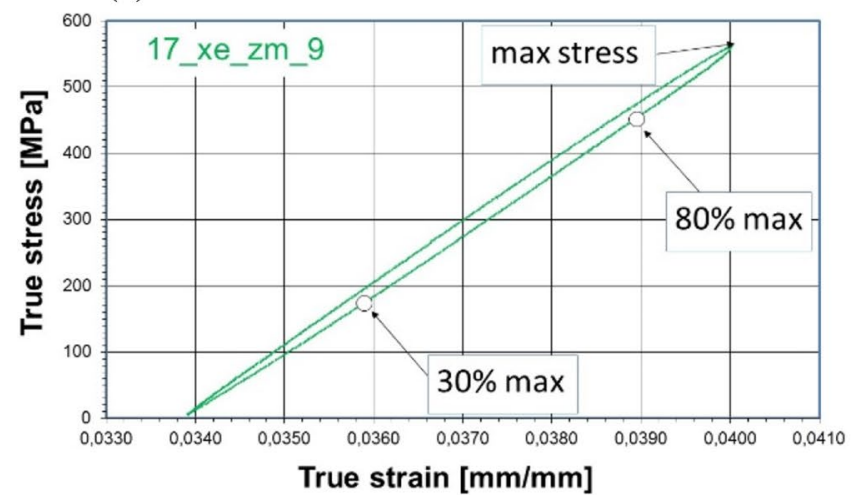

(b)

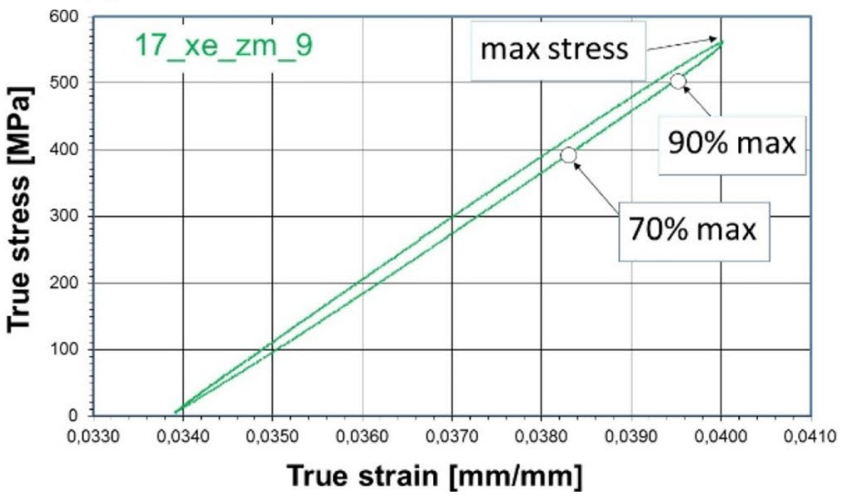

Fig. 6 AA2124+17\% SiC, specimen 17_xe_zm_9: the range of maximum stress level (max stress) obtained at the beginning of unloading for strain equal 4\%: (a) 80-30\%; (b) 90-70\%

once the force value drops to about 0 and then the loading is started again and continues up to engineering strain level equal to $1 \%$ (the strain is increasing again in Fig. 2b) and just afterwards second unloading is performed (the second drop of strain in Fig. 2b). This unloading is called "secondary unloading" and is finished when force value is again equal to about 0 . After that point, loading is continued up to the next engineering strain level equal to $2 \%$ and the procedure is repeated.

The investigations were performed to assess degradation of elastic modulus and damage evolution during tensile tests. It is expected that the measured change of slope for a primary unloading will be affected both by the material degradation due to the damage mechanisms mentioned in the introduction (i.e. fracture of particles, matrix voiding or particle/matrix debonding) and by microplasticity, so the heterogeneous plastic flow in aluminum polycrystalline matrix. The influence of the latter phenomenon is expected to be much reduced during secondary unloading, since strain hardening increases the range of the linear elastic response for the metal phase. Therefore, the use of two unloading loops in the present experimental procedure enables us to assess approximately both impacts on the measured value of the current elastic modulus.

The first three unloadings were performed in elastic range (Fig. 3b). In a macroscopic scale, they result in approximately straight lines on the stress-strain curve. However, elastic moduli in this region, assessed using linear regression method, vary according to the range that was analysed and whether the moduli were calculated from loading or from unloading path. During subsequent unloadings, hysteresis loops were obtained (Figs. 4, 5, 6). The hysteresis loops width is larger for primary unloadings in comparison to the secondary ones what indicates cyclic hardening. Furthermore, the higher reinforcement content the larger width of hysteresis loops was observed. Simultaneously, the width of hysteresis loops enlarges for unloadings performed for a higher engineering strain level. 
Elastic moduli were calculated using linear regression, at the beginning of tensile tests and for each unloading in the three ranges:

- from 80 to $30 \%$ (a range situated within the range proposed by Lemaitre [16]);

- from 85 to $60 \%$ (a range between the two other ranges);

- from 90 to 70\% (a range from the upper part of unloading curve);

of maximum stress level at the beginning of each unloading (Fig. 6). Elastic moduli were obtained for the true stress and strain values.

Since the initial elastic moduli of undamaged material should be calculated in the same way as actual elastic moduli of damaged one, initial moduli were calculated from the same ranges as actual elastic moduli of damaged material. The initial moduli were obtained as an average of elastic moduli from second and third unloadings for a given range of maximum stress level. Only initial elastic moduli of 85-60\% range for specimen 17 xe zm 9 and of $80-30 \%$ range for specimen 25_xe_zm_10 were estimated as an average of initial elastic moduli calculated for the two other ranges, since their values vary in comparison to the initial moduli from the other ranges. Additionally, initial modulus for the specimen 17_xe_zm_10 was evaluated from loading path of tensile stress-strain curve.

Current elastic modulus, assessed using linear regression for given ranges of the unloading curves, and respective damage parameter calculated using relation (1) are presented (a)

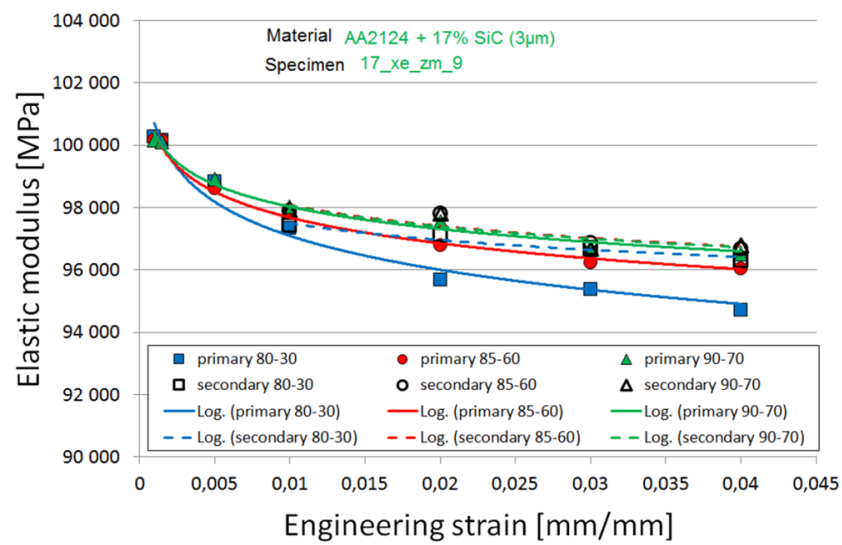

Fig. 7 AA2124+17\% SiC, specimen 17_xe_zm_9. Comparison of elastic moduli (a) and damage parameters (b) for primary and secondary unloadings for ranges (Square plot markers) $80-30 \%$, (Circle (b)

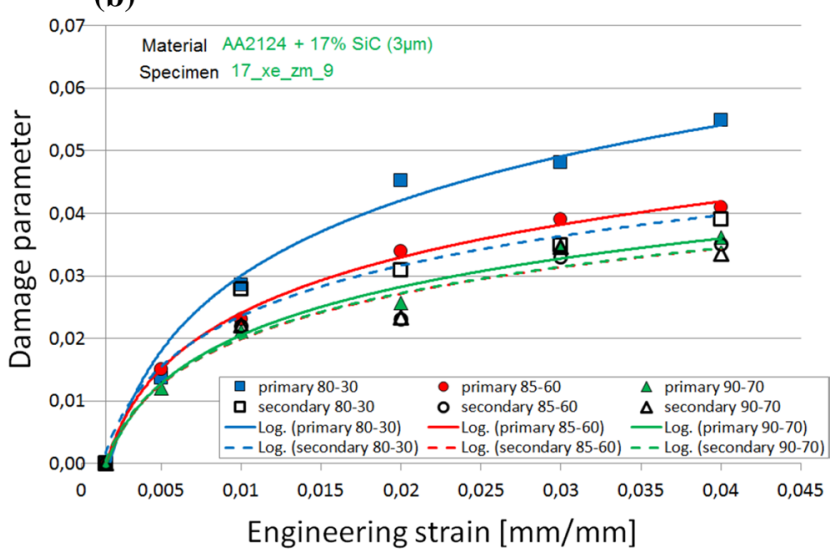

plot markers) $85-60 \%$ and (Triangle plot markers) 90-70\%. Curve log. (secondary 85-60) and log. (secondary 90-70) overlap

(b)

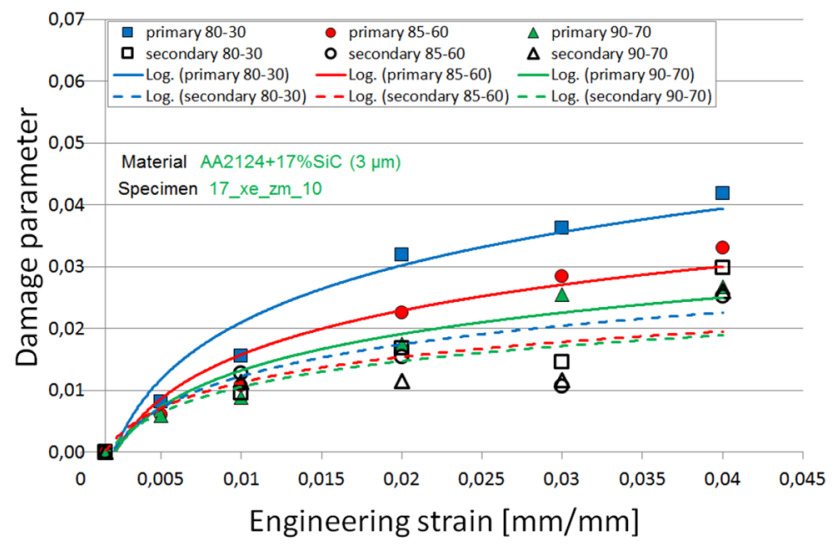

Fig. 8 AA2124+17\% SiC, specimen 17_xe_zm_10. Comparison of elastic moduli (a) and damage parameters (b) for primary and secondary unloadings for ranges (Square) 80-30\%, (Circle) 85-60\% and (Triangle) $90-70 \%$ 
(a)

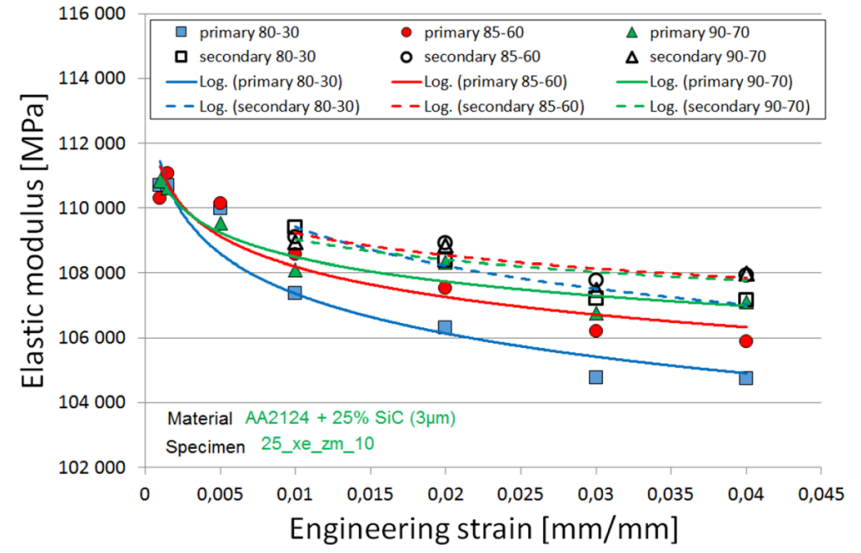

(b)

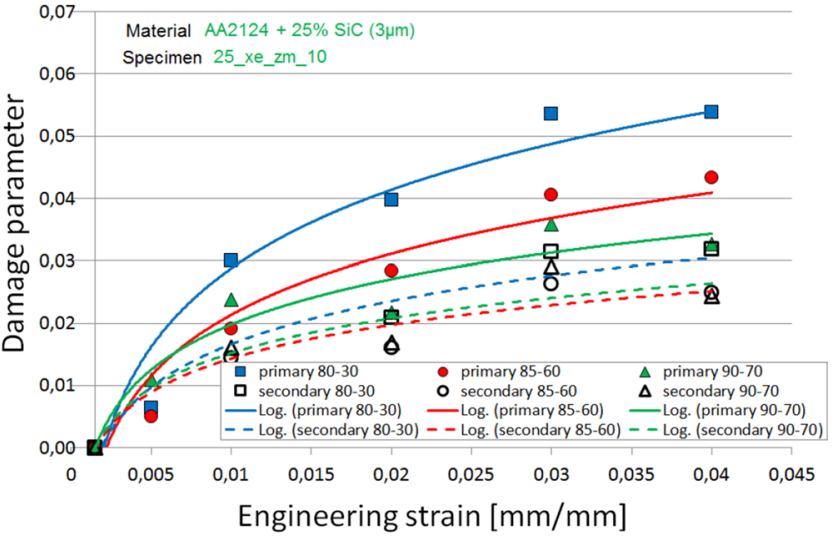

Fig. 9 AA2124 $+25 \% \mathrm{SiC}$, specimen 25_xe_zm_10. Comparison of elastic moduli (a) and damage parameters (b) for primary and secondary unloadings for ranges (Square) 80-30\%, (Circle) 85-60\% and (Triangle) $90-70 \%$

(a)

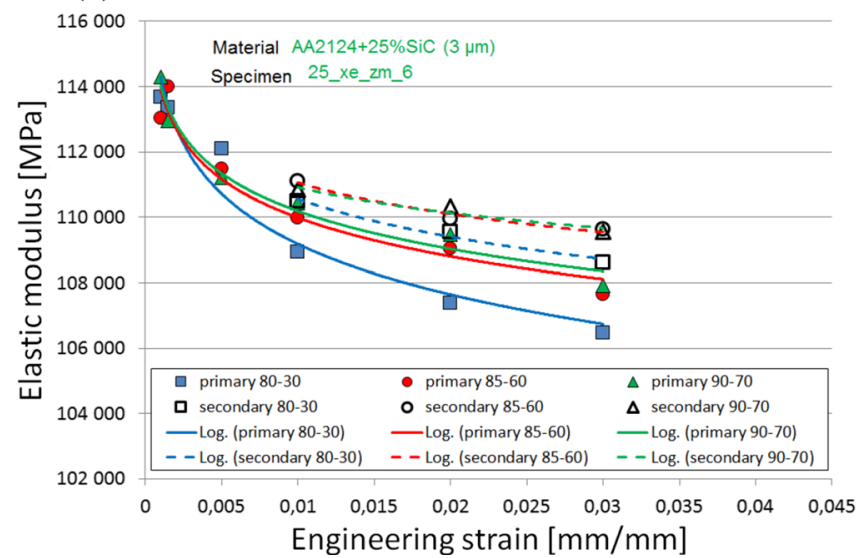

(b)

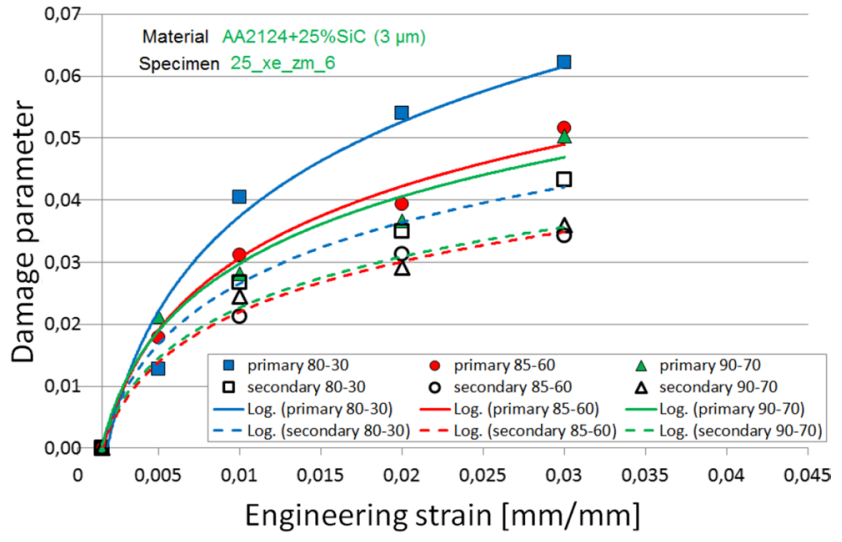

Fig. 10 AA2124+25\% SiC, specimen 25_xe_zm_6. Comparison of elastic moduli (a) and damage parameters (b) for primary and secondary unloadings for ranges (Square) 80-30\%, (Circle) 85-60\% and (Triangle) 90-70\%

in Figs. 7, 8, 9, 10a and b, respectively. Values obtained using the three ranges mentioned above are compared.

In most cases, the higher strain level for the given unloading, the lower elastic moduli values were obtained which indicates damage development during tensile tests. Moreover, elastic moduli calculated for the secondary unloadings were higher than elastic moduli calculated for the primary ones. Higher elastic moduli were also observed for the composite with higher (25\%) SiC content. The obtained values of elastic moduli vary with the range of tensile stress-strain curve that were analysed. For the range $80-30 \%$, which is situated within the range proposed by Lemaitre [16], differences in the values of elastic moduli obtained for the primary and the secondary unloadings were the highest (Figs. 7a, 8a, $9 \mathrm{a}, 10 \mathrm{a}, 11)$. At the same time, the values of elastic moduli assessed for the primary and the secondary unloadings were

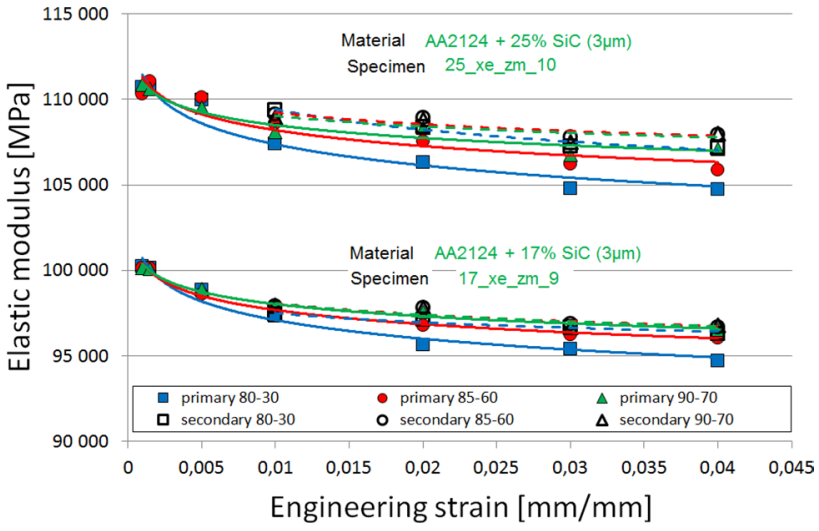

Fig. 11 Comparison of elastic moduli for AA2124+17\% SiC (specimen 17_xe_zm_9) and AA2124+25\%SiC (specimen 25_xe_zm_10) for primary and secondary unloadings for ranges (Square) $80-30 \%$, (Circle) $85-60 \%$ and (Triangle) $90-70 \%$ 
the closest to each other for the range of $90-70 \%$ (at the upper part of unloading curve) (Figs. 7a, 8a, 9a, 10a, 11).

Damage parameters were evaluated using formula (1), where $E$ was calculated during given unloading and $E_{0}$ was obtained in elastic range at the beginning of tensile test. For a given specimen, damage parameters are higher for lower elastic moduli obtained during unloadings. The rate of increase of the damage parameter is the highest at the beginning of tensile test and subsequently decreases. The damage parameter evaluated for primary unloadings reaches higher values in comparison with the one calculated for secondary unloadings. Following elastic moduli, values of damage parameter obtained for the range $80-30 \%$ for the primary and secondary unloadings varied more significantly in comparison with the range of 90-70\% (Figs. 7b, 8b, 9b, 10b). Taking into account the values of damage parameter for the primary unloadings of the range $90-70 \%$, it can be noticed that the values are the closest to the values from the secondary unloadings.

Calculated values of damage parameter are the highest for the primary unloadings for the range $80-30 \%$. The material response in this range is linear in a macroscopic scale, what can be seen in Fig. 6a, while for an entire unloading part of the primary loop it is nonlinear. As expected, contrary to the secondary unloadings, damage parameter calculated for the primary unloading loops is not influenced by cyclic hardening. Consequently, the measured change of slope for a primary unloading is affected both by the material degradation due to the damage mechanisms and by microplasticity in aluminum polycrystalline matrix. This heterogeneous plastic flow is much reduced by strain hardening in the case of secondary unloading. The stress level is increased what then leads to the acceleration of microvoids and microcracks growth, and thus degradation of macroscopic elastic modulus. Reduction of micorplasticity effects also explains why the range $90-70 \%$ taken for both unloading loops gives the closest values of damage parameter: in this initial part of unloading, almost all grains in the polycrystalline matrix remain in the elastic regime.

\section{Microstructure examination}

Metallographic studies were carried out by means of SEM. Based on the observations carried out in the area of the gripping parts of specimens (Fig. 12), it can be concluded that no microstructural degradations or the presence of any voids resulting from the manufacturing process of the materials studied were observed in the microstructure. $\mathrm{SiC}$ clustering and/or $\mathrm{SiC}$ agglomeration are visible (Fig. 12, 13, 14).

The aim of the examination is to determine the microstructure changes observed in tested composites after tensile loading with consecutive unloadings. The characterization of fracture surfaces resulting from mechanical tests has been performed. In addition, the microstructure examination by SEM has been conducted to identify cracks or other material discontinuities occurring after the mechanical tests. The microstructural effects identified during observations performed by SEM are shown in Fig. 13 for the AA2124+17\%SiC (specimen 17_xe_zm_9) and in Fig. 14 for the AA2124+25\% SiC (specimen 25_xe_zm_10).

During microstructural investigations anisotropic arrangement of sites without $\mathrm{SiC}$ particles for AA2124+17\% SiC has been observed (Fig. 13a, d). The effect is not so visible for the composite with higher $25 \%$ content of SiC particles (Fig. 14a, d). Deflection of cracks on reinforcement particles (Figs. 13b, c and 14b, c), cracking (Figs. 13b, e and 14b) and defragmentation of the particles (Figs. 13b, c, e and 14b) for both composites are observed. Additionally, crack bridging by $\mathrm{SiC}$ particles has been identified for AA2124 +25\%SiC (Fig. 14b). The described microstructural effects were observed mainly at the areas near the (a)

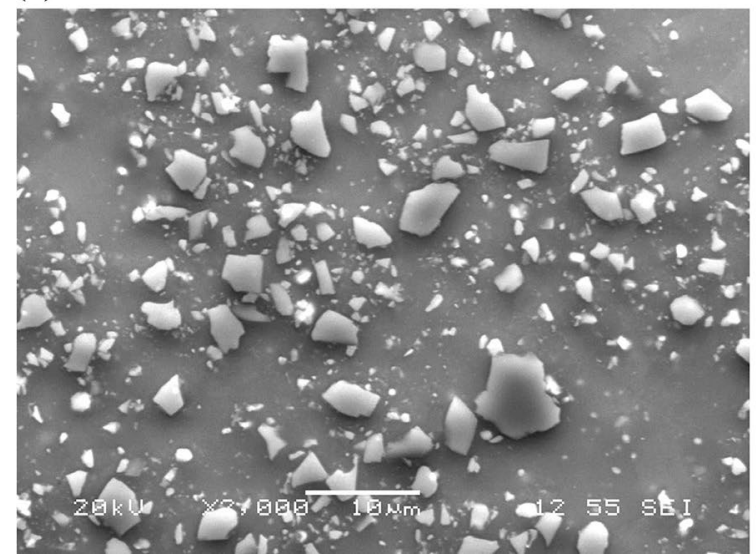

(b)

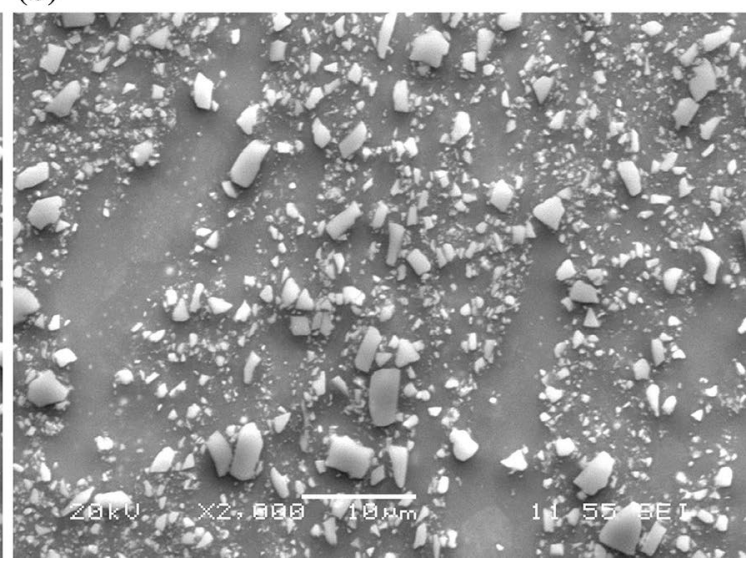

Fig. 12 Microstructural observations carried out in the area of the gripping parts of specimens: (a) AA2124+17\% SiC; (b) AA2124+25\% SiC 
(a), (b), (c) Areas near the tensile fracture surface

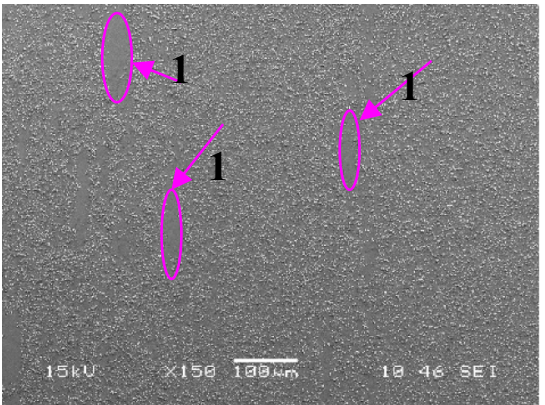

(a) Anisotropic arrangement of sites without $\mathrm{SiC}$ particles, magn. 150x

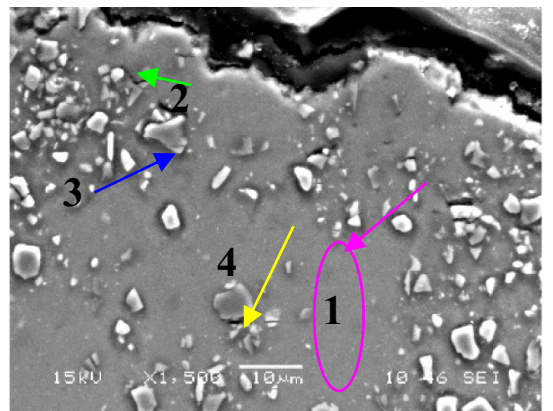

(b) Visible site without $\mathrm{SiC}$, deflection of cracks on $\mathrm{SiC}$ particles, cracking and defragmentation of $\mathrm{SiC}$ particles, magn. $1500 \mathrm{x}$

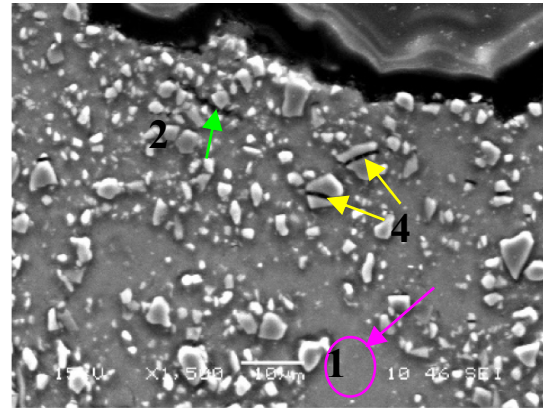

(c) Visible sites without $\mathrm{SiC}$, deflection of cracks on $\mathrm{SiC}$ particles and defragmentation of $\mathrm{SiC}$ particles, magn. $1500 \mathrm{x}$

(d), (e), (f) Areas at a large distance from the tensile fracture surface

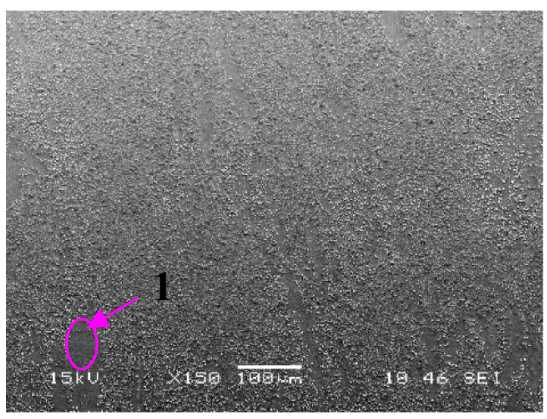

(d) Anisotropic arrangement of sites without SiC particles, magn. 150x

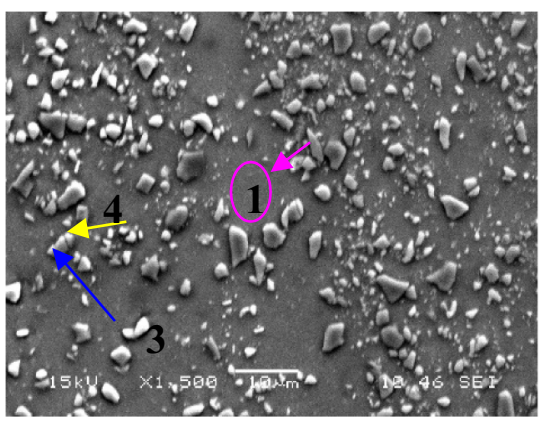

(e) The sites without $\mathrm{SiC}$ particles, the cracks of some $\mathrm{SiC}$ particles and their defragmentation are visible, magn. 1500x

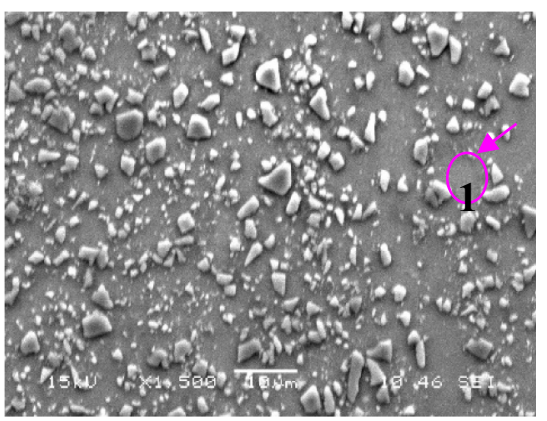

(f) The sites without $\mathrm{SiC}$ particles, the lack of microstructure degradation, magn. $1500 \mathrm{x}$
Fig. 13 Microstructural effects resulted from tensile loading of the AA2124+17\%SiC specimen 17_xe_zm_9, longitudinal cross section: (1) pink - areas without $\mathrm{SiC}$ particles, (2) green-deflection of

tensile fracture surfaces (Fig. 13a, b, c and 14a, b, c). At the areas at a large distance from the tensile fracture surfaces, only some particle cracks and defragmentations have been observed (Fig. 13e).

In the case of specimens subjected to tensile tests with unloadings, it was possible to identify by means of SEM the single crack initiations in fracture surfaces of the composites with $17 \%$ of $\mathrm{SiC}$ as well as $25 \%$ of $\mathrm{SiC}$ contents (Figs. $15 \mathrm{a}$ and $16 a$, respectively).

In Fig. 15a, this crack initiation is noticeable at the edge part of the tensile fracture surface while in Fig. 16a, it is visible in the middle of the tensile fracture surface. The locations of these areas are marked with red (6) arrows. Unless unloadings and subsequent reloadings were performed with very low-speed (strain rate equal to $0.0002 \mathrm{~s}^{-1}$ ) fragments cracks on $\mathrm{SiC}$ particles, (3) blue-cracks of $\mathrm{SiC}$ particles, (4) yellow-defragmentation of $\mathrm{SiC}$ particles

of fracture surfaces and crack initiations look slightly similar to fatigue ones. Simultaneously, taking into account the rest part of the fracture surfaces they can be characterized as brittle.

In addition, the cracks appearing through $\mathrm{SiC}$ particles (7green), cracks occurring around $\mathrm{SiC}$ particles (8-yellow) as well as other microstructural discontinuities (9-white) have been shown in fracture photographs (Figs. 15 and 16).

It can be assumed that initiated small microstructural discontinuities occurring close to each other may undergo coalescence leading to the formation of cracks of greater width and/or length. 
(a), (b), (c) Areas near the tensile fracture surface

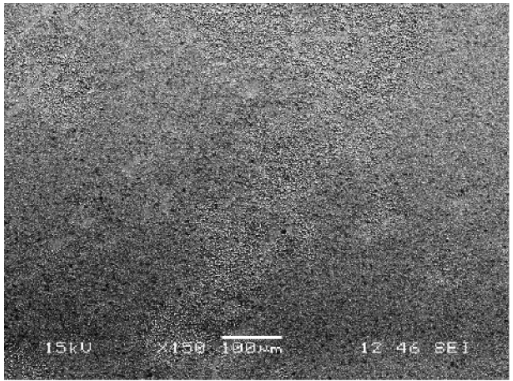

(a) A fairly uniform distribution of the $\mathrm{SiC}$ particles, magn. $150 \mathrm{x}$

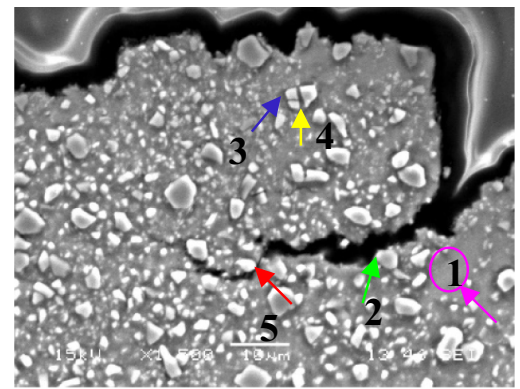

(b) Bridging, deflection of crack on $\mathrm{SiC}$ particles, $\mathrm{SiC}$ particle cracks, their defragmentation and areas without $\mathrm{SiC}$ particles are visible, magn. $1500 x$

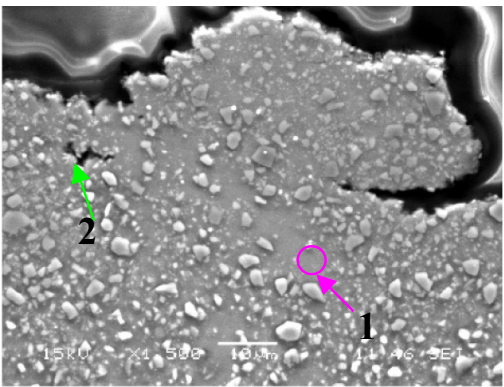

(c) Deflection of crack on $\mathrm{SiC}$ particles and areas without $\mathrm{SiC}$ particles are visible, magn. $1500 x$

(d), (e) Areas at a large distance from the tensile fracture surface - lack of microstructural damage

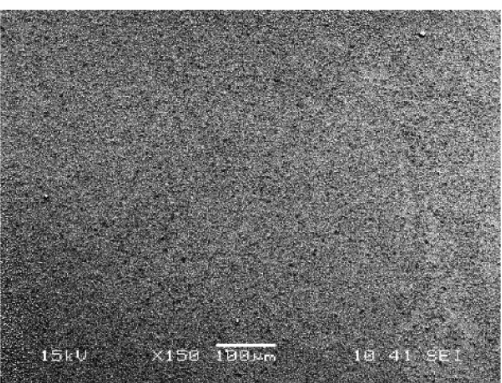

(d) Uniform distribution of the $\mathrm{SiC}$ particles, magn. $150 \mathrm{x}$

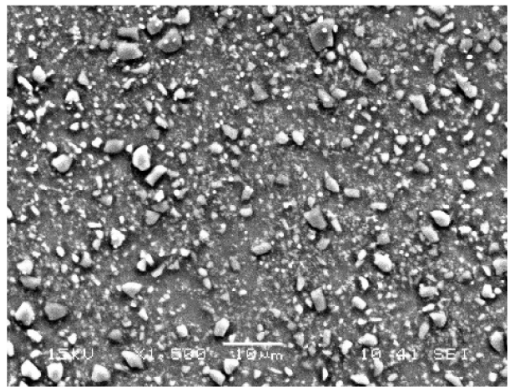

(e) Lack of significant microstructural degradation is visible, magn. $1500 \mathrm{x}$
Fig. 14 Microstructural effects resulted from tensile loading of the AA2124+25\% SiC specimen 25 xe_zm_10, longitudinal cross section: (1) pink-areas without $\mathrm{SiC}$ particles, (2) green-deflection of

\section{Micromechanical modelling of effective properties}

Modelling of effective non-linear properties of the metal-ceramic composites is still a challenge and open problem [37, 38]. Many models exist, but few of them have been verified using real experimental results [32]. In this work, well-known micromechanical averaging schemes of linear overall properties are used for further construction of the methods for prediction of non-linear properties, in particular elasto-plasticity with damage. A wide range of different averaging schemes is available, but at the present stage of research, we take into consideration only the Mori-Tanaka (MT) [39] and self-consistent (SC) [40] schemes. The applied approach requires selection of the linearization method, which has crucial influence on cracks on $\mathrm{SiC}$ particles, (3) blue-cracks of SiC particles, (4) yellow-defragmentation of $\mathrm{SiC}$ particles, (5) red-crack bridging by $\mathrm{SiC}$ particles

the estimates of the macroscopic non-linear properties. Usually, direct linearization is applied incrementally at each step of the analysis, using tangent [40] or secant [41] stiffness moduli of elastic-plastic matrix material. The two linearization methods and their predictions differ significantly from each other, thus both versions are considered in this work. This resulted in a set of predictions of effective non-linear properties.

The effective non-linear properties of the composite are calculated using assumption of isotropy of the composite and its phases. Tangent or secant effective stiffness tensors are anisotropic in general as a result of anisotropy of elastic-plastic tangent stiffness tensor of matrix material [42]. The isotropisation method based on the spectral decomposition [37] of the local tangent stiffness of plastic phase is used in the present study. 


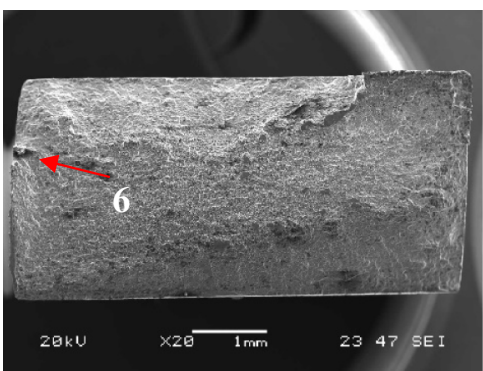

(a) Crack initiation is visible, magn. $20 x$

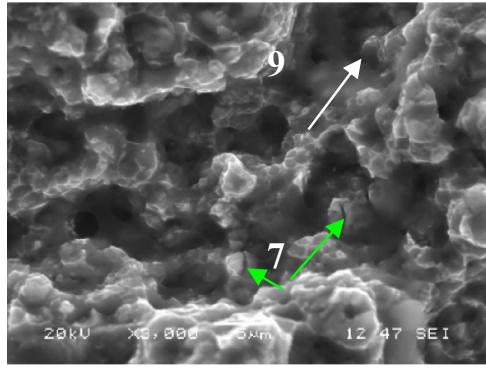

(d) Microstructural discontinuity and cracks occurring through $\mathrm{SiC}$ particles are visible, magn. $3000 \mathrm{x}$

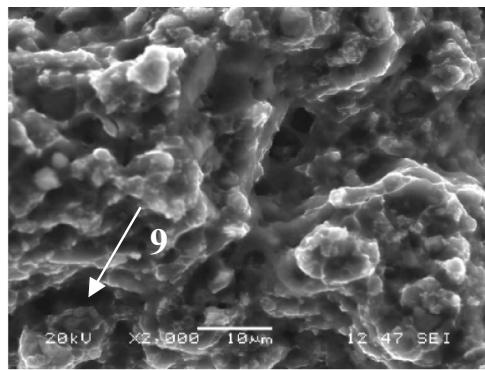

(b) Microstructural discontinuity is visible, magn. $2000 \mathrm{x}$

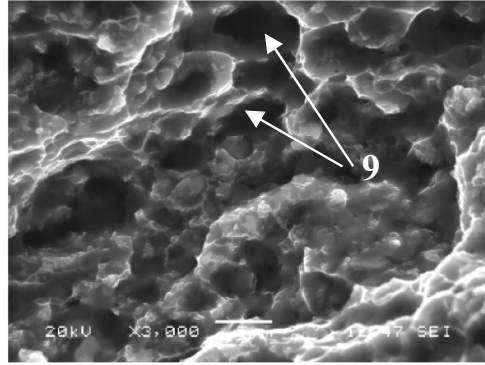

(e) Microstructural discontinuities are visible, magn. $3000 \mathrm{x}$

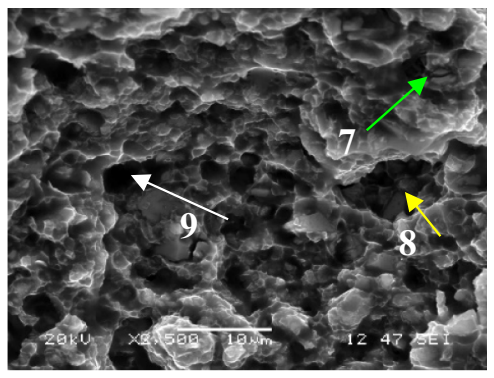

(c) Microstructural discontinuity, cracks occurring around and through $\mathrm{SiC}$ particles are visible, magn. $2500 \mathrm{x}$

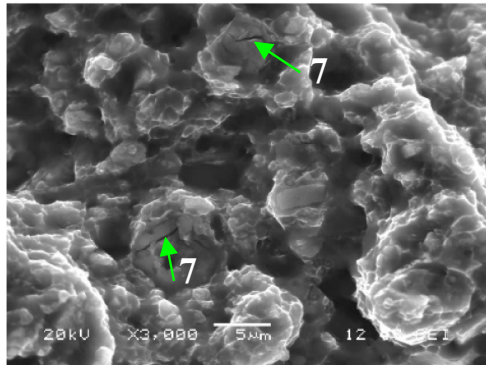

(f) Cracks occurring through $\mathrm{SiC}$ particles are visible, magn. $3000 x$

Fig. 15 Tensile fracture surface of the AA2124+17\%SiC—-specimen 17_xe_zm_9, (6) red—crack initiation, (7) green—crack through SiC particles, (8) yellow—crack around $\mathrm{SiC}$ particles, (9) white—-microstructural discontinuity

The Mori-Tanaka averaging scheme is specified for spherical inclusion embedded into the infinite medium with actual matrix properties. The self-consistent scheme is based on the treatment of ceramic and metal phases as spherical inclusions contained in the matrix with averaged properties. The self-consistent scheme has limitations of applicability for the composites with very high-contrast of properties of both phases, cf. [43]. and literature cited therein. Suitable formulas used for calculation can be found e.g. in [44].

Crucial issue in the modelling of elastic-plastic non-linear properties of the composites is to properly identify a real strain hardening curve of metallic matrix, since its mechanical properties have a significant effect on the macroscopic properties of the overall composite. The use of the data set for metallic matrix from the literature can lead consequently to incorrect value of effective properties of the composite as compared with experimental results, regardless of the selection of averaging schemes and linearization methods. The plastic properties of ductile metallic matrix differ from the conventional metal due to changes in the production process. During the production process microstructure changes can arise e.g. grain refinement during grinding of the metallic powder. Therefore, it is purposeful to perform additional experimental tests of metallic matrix produced by the same method as composite, to get plastic properties and a strain-stress curve. Modelling carried out using the experimental curves for a particular 'composite' with a zero content of the ceramic phase called $0 \% \mathrm{SiC}$ composite, resulted in significantly better results, which confirmed the validity of the hypothesis adopted [32].

Besides the elastic-plastic properties of metallic phase other effects may affect the composite response and complicate modelling of the overall composite behaviour. Degradation of microstructure is one of such additional effects arising in composites during deformation. Various types of damage were observed in the literature as discussed in the introduction. In the investigated composites damage appearing through ceramic particles, damage on interface and damage of metallic matrix are found, see Figs. 13 and 14. Moreover, non-uniform particle distribution is observed. For instance, the sites without $\mathrm{SiC}$ particles are seen in Fig. 13a, d. Thus, in this work the possibility of degradation of elastic properties of the composites by means of damage development in metallic matrix is investigated. This assumption is also consistent with observation made on similar composites, where the main damage mechanism leading to failure is damage appearance in the matrix and the interface decohesion, [45], and where the particles fracture, if it even exists, is not a principal damage mechanism. Therefore, in this work, model of metallic 


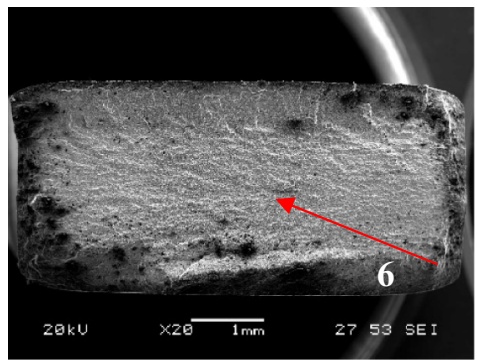

(a) Crack initiation is visible, magn. $20 \mathrm{x}$

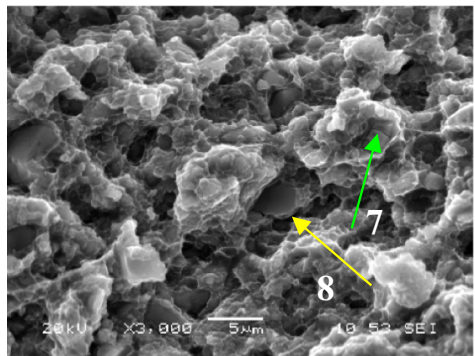

(d) Cracks occurring around and through $\mathrm{SiC}$ particles are visible, magn. $3000 \mathrm{x}$

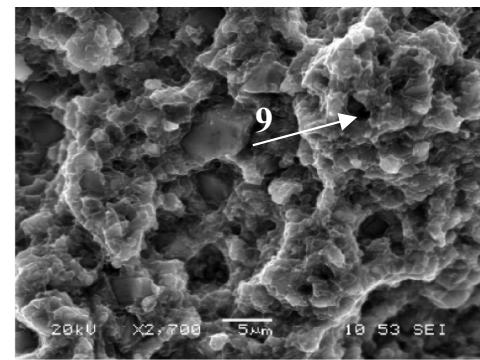

(b) Small microstructural discontinuities are visible magn. 2700x

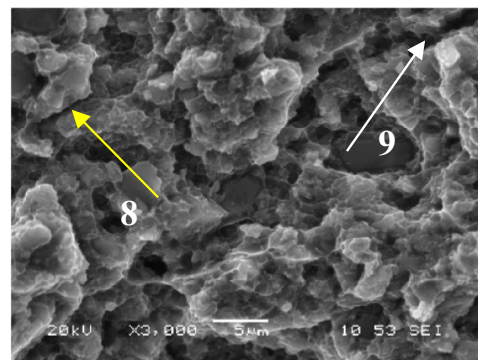

(e) Microstructural discontinuities and cracks around $\mathrm{SiC}$ particles are visible, magn. 3000x

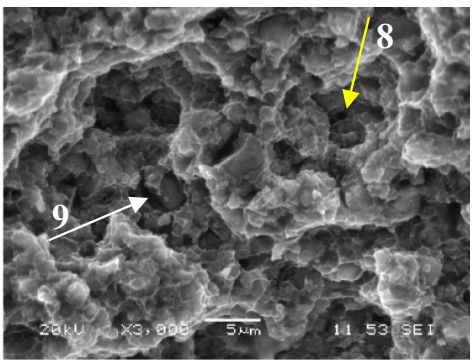

(c) Small microstructural discontinuities and cracks around $\mathrm{SiC}$ particles are visible, magn. 3000x

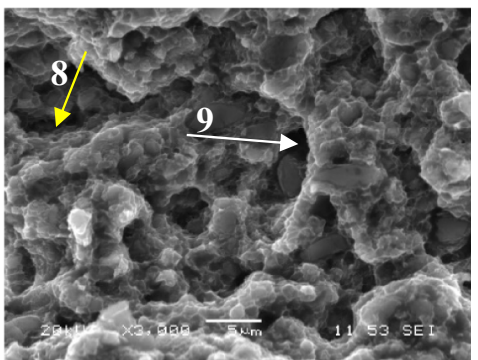

(f) Discontinuities and cracks around $\mathrm{SiC}$ particles are visible magn. 3000x

Fig. 16 Tensile fracture surface of the AA2124+25\%SiC—-specimen 25_xe_zm_10, (6) red—crack initiation, (7) green—crack through SiC particles, (8) yellow—crack around $\mathrm{SiC}$ particles, (9) white—-microstructural discontinuity

phase is extended by taking into account degradation of metal elastic stiffness by means of damage development.

Details of the methodology used for modelling of composite in an elastic-plastic non-linear regime have been described in [32]. Here we focus on extension of the approach necessary to account for the damage development in elastic-plastic metal matrix of a two-phase composite. Let us first recall basic relations for the applied mean-field model. Effective properties of the composite are averaged by micromechanical approach within a representative volume element (RVE). Averaged stress $\overline{\boldsymbol{\sigma}}$ in the composite is calculated at each averaged strain $\bar{\varepsilon}$ using optionally secant

$\overline{\boldsymbol{\sigma}}=\overline{\mathbf{L}}^{\mathrm{s}} \overline{\boldsymbol{\varepsilon}}$

or tangent

$\overline{\boldsymbol{\sigma}}=\overline{\mathbf{L}}^{\mathrm{t}} \overline{\boldsymbol{\varepsilon}}$

linearization of the material response within the RVE. Quantities $\overline{\boldsymbol{\sigma}}$ and $\overline{\boldsymbol{\varepsilon}}$ mean averaged stress and strain rates, respectively. Both, secant $\overline{\mathbf{L}}^{\text {s }}$ and tangent $\overline{\mathbf{L}}^{\mathrm{t}}$ effective tensors are in the form of the fourth-order overall stiffness tensor. In the case of two-phase composites they have the form
$\overline{\mathbf{L}}^{\mathrm{t} / \mathrm{s}}=c_{\mathrm{i}} \mathbf{A}_{\mathrm{i}} \mathbf{L}_{\mathrm{i}}^{\mathrm{t} / \mathrm{s}}+c_{\mathrm{m}} \mathbf{A}_{\mathrm{m}}, \mathbf{L}_{\mathrm{m}}^{\mathrm{t} / \mathrm{s}}, \quad c_{\mathrm{i}}+c_{\mathrm{m}}=1$.

To estimate tangent or secant effective properties of a composite $\overline{\mathbf{L}}^{\mathrm{t} / \mathrm{s}}$, it is necessary to know the volume fraction of the elastic inclusion $c_{\mathrm{i}}$ and elastic-plastic (with damage) matrix $c_{\mathrm{m}}$ as well as the phase properties $\mathbf{L}_{r}^{\mathrm{t} / \mathrm{s}}$. The respective tangent or secant stiffness tensors $\mathbf{L}_{r}$ for phases $(r)$ are calculated for the ceramic inclusions $(r=\mathrm{i})$ and metallic matrix $(r=\mathrm{m})$ by the formula

$\mathbf{L}_{r}^{\mathrm{t} / \mathrm{s}}=3 K_{r}^{\mathrm{t} / \mathrm{s}} \mathbf{I}^{\mathrm{P}}+2 G_{r}^{\mathrm{t} / \mathrm{s}} \mathbf{I}^{\mathrm{D}}$,

where $\mathbf{I}^{\mathrm{P}}$ and $\mathbf{I}^{\mathrm{D}}$ are identity tensors in hydrostatic and deviatoric spaces. It is assumed that both phases $(r)$ are isotropic and described by tangent or secant (t/s) bulk $K_{r}^{\mathrm{t} / \mathrm{s}}$ and shear $G_{r}^{t / s}$ moduli. The ceramic phase is linearly elastic so, both the incremental tangent $\mathbf{L}_{\mathrm{i}}^{\mathrm{t}}$ and secant $\mathbf{L}_{\mathrm{i}}^{\mathrm{s}}$ stiffness tensors are equal to the isotropic elastic stiffness tensor. In general, the current tangent $\mathbf{L}_{\mathrm{m}}^{\mathrm{t}}$ and secant $\mathbf{L}_{\mathrm{m}}^{\mathrm{s}}$ stiffness tensors of metallic matrix which is elastic-plastic with damage, are anisotropic, but, as already mentioned, an isotropised stiffness tensor of metallic matrix is here assumed. Their exact forms are given at work [32] by formulas $(16,18)$ therein, respectively. Note that the tangent linearization is not applicable when metallic phase reaches softening stage, while 
secant linearization is possible only for proportional straining process.

The fourth order concentration tensors $\mathbf{A}_{r}$ are specified for selected micromechanical averaging method-in this work, the Mori-Tanaka and self-consistent model. To specify the formula for concentration tensors $\mathbf{A}_{r}$ the Eshelby's elasticity solution for an inhomogeneity in the form of ellipsoidal inclusion embedded into the infinite medium is used. In this work, the microstructure model contains the inhomogeneity in the form of spherical inclusion. This assumption simplifies the mathematical description of the model. The specific formula for the concentration tensor $\mathbf{A}_{r}$ can be found in [32].

The metallic matrix is modeled using the plastic flow theory along with the standard Huber-von Mises yield function. To take into account damage evolution, decrease in the average elastic modulus of damaged metallic phase is realized by formulas resulting from the expression (1)

$K_{\mathrm{m}}=K_{\mathrm{m}}^{0}(1-d)$ and $G_{\mathrm{m}}=G_{\mathrm{m}}^{0}(1-d)$,

using the damage parameter $d$ determined for the composite from experimental data for selected volume fraction (e.g. Fig. $7 \mathrm{~b}$ ), where $K_{\mathrm{m}}^{0}$ and $G_{\mathrm{m}}^{0}$ are bulk and shear moduli of undamaged metallic phase, respectively. No initial damage of metallic phase and no initial porosity, e.g. due to the manufacturing process is assumed. The damage parameter $d=d\left(\varepsilon_{\mathrm{am}}\right)$ is a function of accumulated total strain in metallic matrix $\varepsilon_{\text {am }}$, see definition (9) below.

Model of metallic matrix is assumed to be elastic-plastic with damage. Stress state in metallic matrix is calculated for hydrostatic and deviatoric part

$\dot{\sigma}^{\mathrm{P}}=3 K_{\mathrm{m}} \dot{\varepsilon}^{\mathrm{Pe}}, \quad \dot{\sigma}^{\mathrm{D}}=2 G_{\mathrm{m}}\left(\dot{\varepsilon}^{\mathrm{D}}-\dot{\varepsilon}^{\mathrm{D} \mathrm{p}}\right)$,

using the elastic modulus of damaged phase (6). The hydrostatic part of strain is elastic $\dot{\varepsilon}^{P}=\dot{\varepsilon}^{\mathrm{Pe}}$, the deviatoric part of strain contains elastic and plastic part $\dot{\varepsilon}^{\mathrm{D}}=\dot{\varepsilon}^{\mathrm{De}}+\dot{\varepsilon}^{\mathrm{Dp}}$. Description of Huber-von Mises yield function $f$, the flow rule and plastic consistency condition can be found in [32], see formulas $(9,10)$ therein.

Simple computational algorithm of the incremental iterative procedure for two-phase elastic-plastic composite materials (without damage modelling) has been described briefly in [32]. It should be noted that in the present work, values of tensors $\mathbf{L}_{\mathrm{m}}^{\mathrm{t}}$ and $\mathbf{L}_{\mathrm{m}}^{\mathrm{s}}$ specified in [32] depend also on the damage parameter $d$ of the metallic matrix since bulk $K_{\mathrm{m}}$ and shear $G_{\mathrm{m}}$ moduli defined by Eq. (6) are used in the cited formulas in place of the constant elastic bulk and shear moduli.

Numerical computations have been carried out for Young's modulus $E_{0}=476 \mathrm{GPa}$ and Poisson's ratio $v=0.19$ for linearly elastic ceramic phases $\mathrm{SiC}$, properties have been found at [46].

As concerns the metallic phase, the identified yield stress is $\sigma_{\mathrm{Y}}=280 \mathrm{MPa}$. Moreover, Young's modulus $E_{0}=77 \mathrm{GPa}$ and Poisson's ratio $v=0.33$ are assumed based on [47]. The strain hardening function $\sigma_{\mathrm{cr}}\left(\varepsilon_{\mathrm{eq}}\right)$ of the metallic phase has been predicted using the developed micromechanical model and the curve for AA2124+17\% SiC composite. The nonlinear isotropic hardening model is used, where hardening moduli of $0 \%$ stress-strain curve of metallic matrix material are reconstructed using linear interpolation (piecewise linear function). Interpolation function has been obtained applying Wolfram Mathematica program. Since the response of AA2 $124+17 \%$ SiC composite matching the experimental data is established using different mean-field and linearization schemes, the corresponding strain hardening function for the metallic phase has been reconstructed for each of these methods independently.

Function

$d\left(\varepsilon_{\mathrm{am}}\right)=A \operatorname{Ln}\left(1+B\left(\varepsilon_{\mathrm{am}}\right)^{C}\right)$,

describing degradation of bulk and shear moduli for metallic matrix, as expressed by Eq. (6), is directly based on the experimental data. Damage parameter function $d\left(\varepsilon_{\mathrm{am}}\right)$ depends on nonnegative strain measure

$\dot{\varepsilon}_{\mathrm{am}}=\sqrt{\dot{\varepsilon}_{\mathrm{m}} \cdot \dot{\varepsilon}_{\mathrm{m}}}$.

Values of damage parameter function $d\left(\varepsilon_{\mathrm{am}}\right)$ can increase until it reaches 1 . The experimental results for both primary and secondary unloading loops within the $90-70 \%$ range are the most consistent (Figs. 7, 8, 9, 10). For this reason, these experimental data were selected for modelling of damage in the composite. Non-dimensional parameters $(A, B, C)$ have been selected so that the function (8) is located equally in between both experimental curves of damage parameters for composite AA2 $124+17 \% \mathrm{SiC}$ for primary and secondary unloading loops within the $90 \%-70 \%$ range (curves shown in Fig. 7b for specimen 17_xe_zm_9). Material properties of phases and parameters of the damage function (8) used in calculations are summarized in Table 1.

Simulated stress-strain curves for composite with $25 \%$ volume fraction of ceramic phase are shown as dashed

Table 1 Material data for the phases used in the model

\begin{tabular}{llll}
\hline Properties & $\begin{array}{l}E_{0} \\
{[\mathrm{GPa}]}\end{array}$ & $v$ & $\begin{array}{l}\sigma_{Y} \\
{[\mathrm{MPa}]}\end{array}$ \\
\hline $\mathrm{SiC}$ & 476 & 0.19 & - \\
$\mathrm{AA} 2124$ & 77 & 0.33 & 280 \\
$\begin{array}{l}\text { Parameters of damage function (8) } \\
\text { based on }\end{array}$ & $\mathrm{A}$ & $\mathrm{B}$ & $\mathrm{C}$ \\
$\begin{array}{l}\text { AA2124+ 17\%SiC, primary and second- } \\
\text { ary within 90-70\% }\end{array}$ & 0.015 & 93.9 & 0.78 \\
\hline
\end{tabular}


(a)

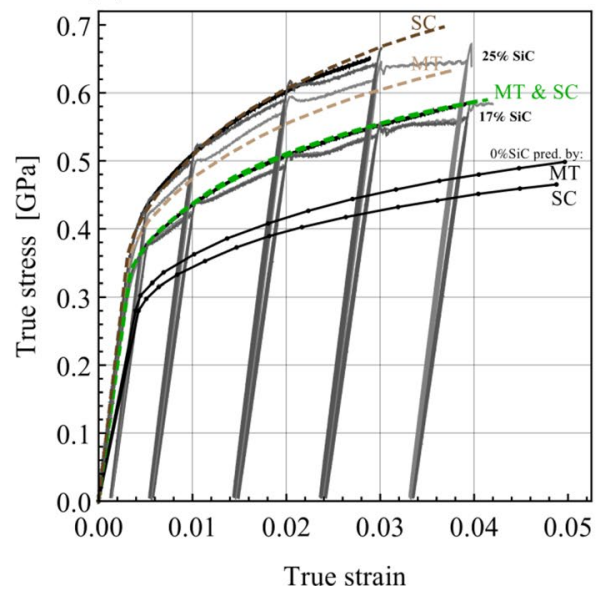

Fig. 17 Comparison of stress-strain response in uniaxial tension. Black and grey curves have been obtained experimentally, brown and blue dashed curves have been calculated with use of SC and MT averaging schemes using (a) tangent or (b) secant linearization, respectively. Black solid-dotted curves $0 \% \mathrm{SiC}$ MT and SC have been predicted by independently fitting the predictions of MT or SC (b)

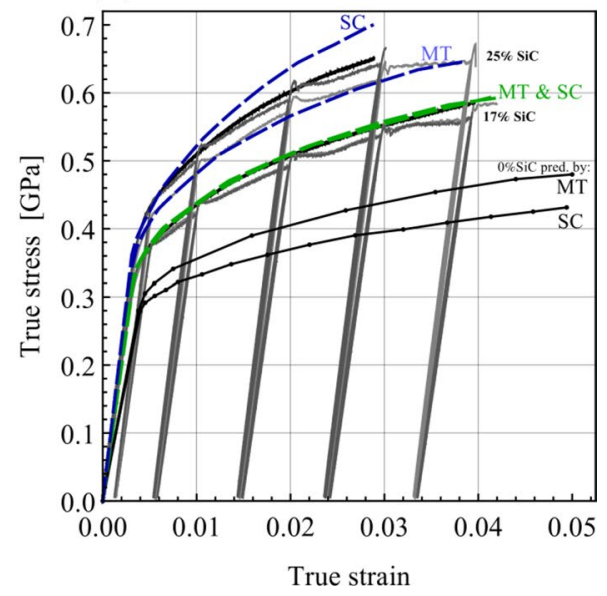

scheme, respectively (shown by dashed green curves in the figure) to experimental results for AA2 $124+17 \% \mathrm{SiC}$ composites. Description of material degradation is based on the damage parameter (8) located equally in between both experimental curves for unloading loops within the $90-70 \%$ range

(b)

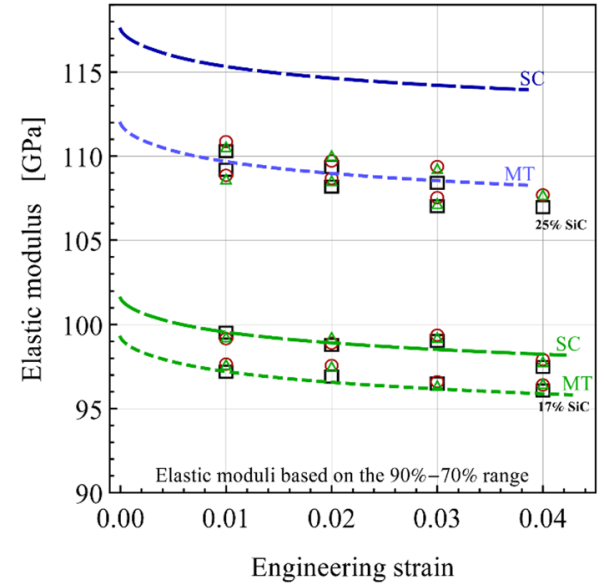

(8) located equally in between both experimental curves for unloading loops within the 90-70\% range. Experimental points for elastic modulus of (a) primary and (b) secondary unloading loops are shown as full and empty marks for ranges (Filled Square) (Square) $80-30 \%$, (Filled Circled) (Circle) 85-60\% and (Filled Triangle) (Triangle) 90$70 \%$, respectively

shown as thin black and thin gray solid lines. Additionally, backextrapolated curves of AA2124 aluminium alloy material ( $0 \% \mathrm{SiC}$ composite curves) are shown as black soliddotted curves for MT and SC method, independently.

Comparing linearization methods, we can see that use of secant linearization results in a stiffer response as compared with unloading loops, for both $17 \%$ and $25 \%$ composites are 
to tangent. Calculations performed for AA2 $124+25 \% \mathrm{SiC}$ using MT averaging scheme predict a softer response than the SC schemes for both types of linearization. The best agreement with experiments is obtained using SC averaging scheme combined with tangent linearization, small deviation is only seen for strains above 0.02 . The MT schemes with tangent and secant linearization are close to each other and both provide satisfactory predictions, especially for secant method, but they are somewhat below experimental curves.

Predicted evolution of the elastic modulus of AA2124 + 25\% SiC composite, obtained using tangent and secant linearization (as dashed blue lines) and two averaging schemes are compared with experiments in Fig. 18. Results of both simulations, based on one damage parameter function (8), for primary in Fig. 18a and secondary in Fig. 18b unloading loops are shown. Both linearization method deliver almost the same result of elastic modulus when using the same averaging scheme; therefore, respective curves overlap. It can be seen that for AA2124 + 25\% SiC composite the MT scheme provides good agreement with the experimental data for elastic modulus based on the primary as well as secondary loops. The SC scheme clearly overestimates both experimental results, what results from the initial value of elastic modulus overpredicted by the SC scheme. Note that the green curves calculated for AA2 $124+17 \% \mathrm{SiC}$ composites should be treated as fitting curves. In summary, taking into account both, the predictions of stress-strain composite response and damage evolution, the Mori-Tanaka variant combined with the secant linearization method provided the best predictions when compared with the experimental data.

\section{Summary and conclusions}

The performed studies lead to the following conclusions. Damage parameter calculated on the basis of elastic moduli obtained during subsequent unloadings in most cases increases during tensile tests. The increase is more significant at the beginning of tension but continues with lower speed up to specimen fracture. The primary unloadings give as a result higher damage parameter values in comparison to secondary ones. The damage parameter values are the highest for $80-30 \%$ range of primary unloadings. The material response in this range is linear in a macroscopic scale, while for the entire unloading loop is nonlinear. Moreover, this range seems to be not influenced by such mechanisms as cyclic hardening during subsequent cycles.

Considering secondary unloadings, the material response is more linear in the entire range of hysteresis loops in comparison to primary ones. Damage parameter values obtained for the upper range of unloading loops are more similar for primary and secondary unloadings in comparison to the other ranges. The range of $90-70 \%$ for primary unloadings gives the elastic moduli and damage parameters values the most similar to the values from secondary unloadings.

The observed differences between the material behaviour during primary and secondary unloading can be explained as follows. The observed change of slope for a primary unloading results from both by the material degradation due to damage and by microplasticity (i.e. heterogeneous plastic flow in aluminum polycrystalline matrix). The influence of the latter phenomenon is much reduced during secondary unloading. The range $90-70 \%$ taken for both unloading loops gives the closest values of damage parameter because in the initial part of unloading almost all grains in the polycrystalline matrix remain in the elastic regime. Following this reasoning, the use of two unloading loops in the proposed experimental procedure makes it possible to assess approximately both impacts on the current elastic modulus.

Based on structural examination of the composites using SEM methods, the occurrence of the crack deflection mechanism on SiC particles and/or bridging of these cracks by the reinforcing particles were found. Applied mechanical loading also led to the formation of cracks of reinforcing particles, often leading to their defragmentation and the formation of the other material discontinuities in the matrix. It should be emphasized that all the mentioned microstructural effects of mechanical loading are mainly limited to the areas located close to the fracture surface of the specimens. In the case of composite reinforced with $25 \% \mathrm{SiC}$, more cracks and discontinuities were formed and they were larger as compared to the composite containing 17\% SiC. Probably this effect results from the coalescence of cracks and small discontinuities located close to each other. Moreover, in both composites subjected to the tensile tests with unloadings, initiation and formation of single cracks slightly similar to fatigue ones has been identified. However, the rest part of the fracture surfaces can be treated as brittle.

Analytical estimates of effective elastic-plastic properties of two-phase composites have been used for calculation of behaviour of AA2124/SiC metal matrix composites. With this aim, the method and algorithm developed in [32] have been extended to account for the possibility of damage development. The self-consistent (SC) and Mori-Tanaka (MT) schemes in combination with the incremental tangent or secant linearization procedures have been implemented. The main difficulty in the numerical modelling was that the properties of individual phases of the composite were not available. For this reason, the methodology for reconstruction of elastic and elastic-plastic properties of two phases using properties of AA2124+17\% SiC composite has been worked out. Identified phase properties were next used for modelling of AA2124+25\% SiC composite. To capture material degradation during deformation, the occurrence of 
damage development in the metallic phase has been assumed in both variants of micromechanical model. As suggested by experimental observations values of macroscopic damage parameter measured for $90-70 \%$ unloading ranges in the primary and secondary loops for AA2124+17\% SiC composite have been used for identification of evolution of the damage parameter in metallic phase. The results of analytical simulations have been compared with the results of tensile tests. Both, the self-consistent (SC) and Mori-Tanaka (MT) estimates lead to the satisfactory predictions and agree quite well with experimental results for AA2124 + 25\% SiC composite in terms of strain-stress curve predictions. The MT scheme provides also a good agreement with the experimental data for the change of composite elastic modulus based on the secondary loops.

Acknowledgements The results presented in this paper have been obtained within the project "KosDeKom" (project no. 1576/B/ T02/2011/40) with the National Science Center, Poland.

Funding This work was partially financed by the Polish National Science Centre (NCN) within the project "KosDeKom" (No. 1576/B/ T02/2011/40)

\section{Compliance with ethical standards}

Conflict of interest The authors declare that they have no conflict of interest.

Ethical approval This article does not contain any studies with human participants or animals performed by any of the authors.

Open Access This article is licensed under a Creative Commons Attribution 4.0 International License, which permits use, sharing, adaptation, distribution and reproduction in any medium or format, as long as you give appropriate credit to the original author(s) and the source, provide a link to the Creative Commons licence, and indicate if changes were made. The images or other third party material in this article are included in the article's Creative Commons licence, unless indicated otherwise in a credit line to the material. If material is not included in the article's Creative Commons licence and your intended use is not permitted by statutory regulation or exceeds the permitted use, you will need to obtain permission directly from the copyright holder. To view a copy of this licence, visit http://creativecommons.org/licenses/by/4.0/.

\section{References}

1. Chawla N, Shen Y-L. Mechanical behavior of particle reinforced metal matrix composites. Adv Eng Mater. 2001;3(6):357-70. https ://doi.org/10.1002/1527-2648(200106)3:6<357:AID-ADEM3 57>3.0.CO;2-I.

2. Das DK, Mishra PCh, Singh S, Thakur RK. Properties of ceramic-reinforced aluminium matrix composites-a review. Int J Mech Mater Eng. 2014;1:12. https://doi.org/10.1186/s4071 2-014-0012-9.

3. Kouzeli M, Weber L, San Marchi C, Mortensen A. Quantification of microdamage phenomena during tensile straining of high volume fraction particle reinforced aluminium. Acta
Mater. 2001;49(3):497-505. https://doi.org/10.1016/S1359 -6454(00)00334-7.

4. Kouzeli M, Weber L, San Marchi C, Mortensen A. Influence of damage on the tensile behaviour of pure aluminium reinforced with $\geq 40$ vol. pct alumina particles. Acta Mater. 2001;49(18):3699-709. https://doi.org/10.1016/S1359 $-6454(01) 00279-8$.

5. Maire E, Verdu C, Lormand G, Fougeres R. Study of the damage mechanisms in an OSPREYTM $\mathrm{A} 1$ alloy-SiC $\mathrm{p}_{\mathrm{p}}$ composite by scanning electron microscope in situ tensile tests. Mater Sci Eng A. 1995;196:135-44.

6. Doel TJA, Bowen P. Tensile properties of particulate-reinforced metal matrix composites. Compos A. 1996;27(8):655-65. https ://doi.org/10.1016/1359-835X(96)00040-1.

7. Srivatsan T, Mattingly J. Influence of heat treatment on the tensile properties and fracture behaviour of an aluminium alloy-ceramic particle composite. J Mater Sci. 1993;28(3):611-20. https://doi. org/10.1007/BF01151235.

8. Rutecka A, Kowalewski ZL, Makowska K, Pietrzak K, Dietrich L. Fatigue damage of $\mathrm{Al} / \mathrm{SiC}$ composites-macroscopic and microscopic analysis. Arch Metall Mater. 2015;60(1):101-5. https://doi. org/10.1515/amm-2015-0016.

9. Rutecka A, Kowalewski ZL, Pietrzak K, Dietrich L, Makowska K, Woźniak J, Kostecki M, Bochniak W, Olszyna A. Damage development of $\mathrm{Al} / \mathrm{SiC}$ metal matrix composite under fatigue, creep and monotonic loading conditions. Procedia Eng. 2011;10:1420-5. https://doi.org/10.1016/j.proeng.2011.04.236.

10. Gatea S, Ou H, McCartney G. Deformation and fracture characteristics of A16092/SiC/17.5p metal matrix composite sheets due to heat treatments. Mater. Charact. 2018;142:365-76. https ://doi.org/10.1016/j.matchar.2018.05.050.

11. Shang JK, Ritchie RO. Crack bridging by uncracked ligaments during crack growth in SiC-reinforced aluminum-alloy composites. Metall Trans. 1989;20(5):899-908. https://doi.org/10.1007/ BF02651656.

12. Qin C, Wang L, Jiang W, Bai S, Chen L. Microstructure characterization and mechanical properties of $\mathrm{TiSi}_{2}-\mathrm{SiC}_{\mathrm{C}} \mathrm{Ti}_{3} \mathrm{SiC}_{2}$ composites prepared by spark plasma sintering. Mater Trans. 2006;47(3):845-8. https://doi.org/10.2320/matertrans.47.845.

13. Zhang G-J, Yue X-M, Watanabe T, Yagishita O. In situ synthesis of $\mathrm{Mo}(\mathrm{Si}, \mathrm{Al})_{2}-\mathrm{SiC}$ composites. J Mater Sci. 2000;35:4729-33. https://doi.org/10.1023/A:1004811308556.

14. Chen $\mathrm{Z}, \mathrm{He} P$, Chen $\mathrm{L}$. The role of particles in fatigue crack propagation of aluminum matrix composites and casting aluminum alloys. J Mater Sci Technol. 2007;23(2):213-6.

15. Rocha-Rangel E, Refugio-García E, Miranda-Hernández JG, Terrés-Rojas E. Fracture toughness enhancement for metalreinforced alumina. J Ceram Proc Res. 2009;10(6):744-7.

16. Lemaitre J. A course on damage mechanics. 2nd ed. Berlin, Heidelberg: Springer-Verlag; 1996. https://doi.org/10.1007/9783-642-18255-6.

17. Celentano DJ, Chaboche J-L. Experimental and numerical characterization of damage evolution in steels. Int J Plasticity. 2007;23(10-11):1739-62. https://doi.org/10.1016/j.ijpla s.2007.03.008.

18. Bonora N. Identification and measurement of ductile damage parameters. J Strain Anal Eng Des. 1999;34(6):463-78. https ://doi.org/10.1243/0309324991513894.

19. Lemaitre J, Dufailly J. Damage measurements. Eng Fract Mech. 1987;28(5-6):643-61. https://doi.org/10.1016/00137944(87)90059-2 special Issue in Honor of Professor Takeo Yokobori.

20. Bonora N, Ruggiero A, Gentile D, De Meo S. Practical applicability and limitations of the elastic modulus degradation technique for damage measurements in 
ductile metals. Strain. 2011;47(3):241-54. https://doi.org/10. 1111/j.1475-1305.2009.00678.x.

21. Suquet P. Effective properties of nonlinear composites. In: Suquet $\mathrm{P}$, editor. Continuum micromechanics. CISM lecture notes, vol. 377. New York: Springer; 1997. p. 197-264. https://doi. org/10.1007/978-3-7091-2662-2_4

22. Geers MGD, Kouznetsova VG, Matouš K, Yvonnet J. Homogenization methods and multiscale modeling: nonlinear problems. In: Stein E, Borst R, Hughes TJR (eds) Encyclopedia of computational mechanics. 2nd ed. 2017. https://doi.org/10.1002/97811 19176817.ecm2107

23. Kouznetsova VG, Brekelmans WAM, Baaijens FPT. An approach to micro-macro modeling of heterogeneous materials. Comput Mech. 2001;27:37-48. https://doi.org/10.1007/s004660000212.

24. Gornet L, Marguet S, Marckmann G. Modeling of Nomex® honeycomb cores, linear and nonlinear behaviors. Mech Adv Mater Struct. 2007;14(8):589-601. https://doi.org/10.1080/1537649070 1675370.

25. Llorca J. Deformation and damage in particle-reinforced composites: experiments and model. In: Böhm HJ, editor. Mechanics of microstructured materials. International Centre for Mechanical Sciences (Courses and Lectures), vol. 464. Vienna: Springer; 2004. p. 87-124. https://doi.org/10.1007/978-3-7091-2776-6_4.

26. Basista M, Węglewski W. Modelling of damage and fracture in ceramic matrix composites-an overview. J Theor Appl Mech. 2006;44(3):455-84.

27. Eckschlager A, Han W, Böhm HJ. A unit cell model for brittle fracture of particles embedded in a ductile matrix. Comput Mater Sci. 2002;25(1-2):85-91. https://doi.org/10.1016/S0927 $-0256(02) 00252-5$.

28. Segurado J, LLorca J. A new three-dimensional interface finite element to simulate fracture in composites. Int J Solids Struct. 2004;41(11-12):2977-93. https://doi.org/10.1016/j.ijsol str.2004.01.007.

29. Benabou L, Benseddiq N, Nä̈-Abdelaziz M. Comparative analysis of damage at interfaces of composites. Compos B. 2002;33(3):215-24. https://doi.org/10.1016/S1359 $-8368(02) 00004-5$.

30. Bonfoh N, Lipinski P. Ductile damage micromodeling by particles' debonding in metal matrix composites. Int J Mech Sci. 2007;49(2):151-60. https://doi.org/10.1016/j.ijmec sci.2006.08.015.

31. LLorca J, Segurado J. Three-dimensional multiparticle cell simulations of deformation and damage in sphere-reinforced composites. Mater Sci Eng A. 2004;365(1-2):267-74. https://doi. org/10.1016/j.msea.2003.09.035.

32. Kursa M, Kowalczyk-Gajewska K, Lewandowski MJ, Petryk H. Elastic-plastic properties of metal matrix composites: validation of mean-field approaches. Eur J Mech A Solids. 2018;68:53-66. https://doi.org/10.1016/j.euromechsol.2017.11.001.

33. Chaboche JL, Kruch S, Maire JF, Pottier T. Towards a micromechanics based inelastic and damage modeling of composites. Int J Plast. 2001;17:411-39. https://doi.org/10.1016/S0749 -6419(00)00056-5.

34. Smaga M, Walther F, Eifler D. Monotonic and cyclic deformation behaviour of the $\mathrm{SiC}$ particle-reinforced aluminium matrix composite AMC225xe. Adv Eng Mater. 2010;12(4):262-8. https ://doi.org/10.1002/adem.200900345.
35. A. Rutecka, Nowoczesne kompozyty w osnowie metalowej (MMC) AA2124/SiC w warunkach rozciągania, zmęczenia i pełzania- pierwszy krok do wykrywania oraz szacowania uszkodzeń, W.J. Gilewski (ed.), Wybrane zagadnienia współczesnej inżynierii lądowej, Monografia Wydziału Inżynierii Lądowej, (2018) 155-170, Warszawa.

36. Winter L, Hockauf K, Lampke T. Temperature and particle size influence on the high cycle fatigue behavior of the $\mathrm{SiC}$ reinforced 2124 aluminum alloy. Metals. 2018;8(1):43. https://doi. org/10.3390/met8010043.

37. Chaboche J-L, Kanouté P, Roos A. On the capabilities of meanfield approaches for the description of plasticity in metal matrix composites. Int J Plasticity. 2005;21(7):1409-34. https://doi. org/10.1016/j.ijplas.2004.07.001.

38. Sadowski P, Kowalczyk-Gajewska K, Stupkiewicz S. Consistent treatment and automation of the incremental Mori-Tanaka scheme for elasto-plastic composites. Comput Mech. 2017;60(3):493-511. https://doi.org/10.1007/s00466-017-1418-z.

39. Mori T, Tanaka K. Average stress in matrix and average elastic energy of materials with misfitting inclusions. Acta Metall. 1973;21(5):571-4. https://doi.org/10.1016/0001-6160(73)90064 $-3$.

40. Hill R. Continuum micro-mechanics of elastoplastic polycrystals. J Mech Phys Solids. 1965;13(2):89-101. https://doi. org/10.1016/0022-5096(65)90023-2.

41. Tandon GP, Weng GJ. A theory of particle-reinforced plasticity. ASME J Appl Mech. 1988;55(1):126-35. https://doi. org/10.1115/1.3173618.

42. Doghri I, Ouaar A. Homogenization of two-phase elasto-plastic composite materials and structures. Study of tangent operators, cyclic plasticity and numerical algorithms. Int J Solids Struct. 2003;40:1681-712. https://doi.org/10.1016/S0020 -7683(03)00013-1.

43. Christensen R, Lo K. Solutions for effective shear properties in three phase sphere and cylinder models. J Mech Phys Solids. 1979;27(4):315-30. https://doi.org/10.1016/0022-5096(79)90032 $-2$.

44. Christensen R. Mechanics of composite materials. New York: Dover Publications; 2005.

45. E. Martín, A. Forn, M.T. Baile, J.A. Picas. Influence of heat treatments on mechanical properties of 2124 aluminium matrix composites. In: International Conference on innovative solutions for the advancement of the transport industry, San Sebastián, Spain, 4th-6th October 2006.

46. Ferro-Ceramic Grinding Inc. Ceramic Properties Tables. https:// www.ferroceramic.com/Silicon Carbide_table.htm (Last accessed: 2nd June 2020).

47. eFunda, Inc. Mechanical properties of wrought AA2124. https:// www.efunda.com (Last accessed: 2nd June 2020).

Publisher's Note Springer Nature remains neutral with regard to jurisdictional claims in published maps and institutional affiliations. 